\title{
Thermal-hydraulic transient analysis of the FFTF LOFWOS Test \#13
}

\author{
Vincenzo Narcisi*, Cristiano Ciurluini, Fabio Giannetti, Gianfranco Caruso \\ DIAEE - Nuclear Section, “Sapienza” University of Rome, Corso Vittorio Emanuele II, 244, 00186, Rome, Italy \\ *Corresponding author
}

\section{Abstract}

In the framework of a Coordinate Research Project (CRP) endorsed by the International Atomic Energy Agency (IAEA), the Department of Astronautical, Electrical and Energy Engineering (DIAEE) of Sapienza University of Rome has developed a thermal-hydraulic model of the Fast Flux Test Facility (FFTF). FFTF was a Sodium-cooled Fast Reactor (SFR) developed by the Westinghouse Electric Corporation for the U.S. Department of Energy, which operated from 1980 to 1992 . The main mission of the reactor was to prove feasibility and operation of SFR nuclear power plants. For this purpose, FFTF was designed as a flexible system and extensively instrumented, making it attractive for code validation purposes. The proposed benchmark exercise involves a Loss Of Flow Without Scram (LOFWOS) test, performed in 1986. DIAEE has developed and is validating a multiphysics modelling based on a Neutron-Kinetic/Thermal-Hydraulic (NK/TH) coupling approach with RELAP5-3D ${ }^{\odot}$ and PHISICS codes. The present paper deals with the assessment of the standalone TH modelling, establishing the basis for the next NK/TH phase. Steady-state results have been compared with benchmark specifications, proving the adequacy of the model calibration. After that, the comparison between transient simulation and experimental data has highlighted an overall good agreement, demonstrating the capability of the developed TH nodalization to reproduce the FFTF LOFWOS Test \#13. Outside of the parameters selected for the comparison in the benchmark exercise, outlet plenum thermal stratification and sodium free surface motion within Gas Expansion Modules (GEM) have been analysed, providing useful outcomes for the understanding of the transient event and for future perspectives.

\section{Keywords}

RELAP5-3D, GEM Gas Expansion Module, Sodium cooled Fast Reactor, Loss of Flow Without Scram, Thermal Stratification.

\section{Introduction}

The International Atomic Energy Agency (IAEA) promoted a Coordinated Research Project (CRP) for the Fast Flux Test Facility (FFTF) Loss Of Flow Without Scram (LOFWOS) test. The CRP deals with the assessment of existing computer codes in simulating a safety-relevant scenario involved in Liquid Metal-cooled Fast Reactors (LMFR) (Sumner, 2018). FFTF was a $400 \mathrm{MW}_{\text {th }}$ loop-type Sodium-cooled Fast Reactor (SFR), designed by the Westinghouse Electric Corporation for the U.S. Department of Energy and operated from 1980 to 1992 . The main mission of this reactor was to qualify full-size nuclear fuels and components for the SFR development (Wootan et al., 2017a). For this reason, it was designed as a flexible system, without electrical generation purposes, and as an extensively instrumented test reactor (Wootan et al., 2017b), making it useful not only for SFR qualification 
Nuclear Engineering and Design, 383 (2021) 111405, https://doi.org/10.1016/i.nucengdes.2021.111405

but also for supporting the validation of computer codes and models for safety analysis of LMFR. Indeed, validation process is required to use numerical tools for the assessment of natural phenomena involved in LMFR passive safety systems.

The benchmark analysis involves the LOFWOS Test \#13, belonging to a series of unprotected transients carried out as part of the passive safety testing program in 1986 (Sumner, 2018). The primary goal of that program was to confirm safety margins of FFTF, as an SFR demonstrator, and to verify safety benefits of its peculiar passive devices (Nguyen, 1989). Furthermore, experimental tests provided an extensive database for computer codes validation.

In this framework, the Department of Astronautical, Electrical and Energy Engineering (DIAEE) of Sapienza University of Rome has developed and is validating a multiphysics modelling based on a NeutronKinetic/Thermal-Hydraulic (NK/TH) coupling approach with RELAP5-3D ${ }^{\odot}$ (R5-3D) and PHISICS codes (Giannetti, 2018; Alfonsi et al., 2019). This methodology has been already applied by Del Nevo and Martelli (2016), in the frame of the benchmark analyses of the shutdown heat removal tests performed in the EBR-II Reactor (Briggs, 2013), and by Ciurluini et al. (2020), for the preliminary NK/TH calculations of unprotected transients in the Advanced Lead-cooled Fast Reactor European Demonstrator (ALFRED).

The present paper deals with the assessment of the Thermal-Hydraulic (TH) standalone model, focusing on the TH parameters selected as figures of merit for the benchmark exercise. For this scope, the work presented in this paper has been carried imposing a power vs. time table (NK/TH coupling calculations have been not considered in this phase of the activity). However, a detailed reactor core modelling has been developed, allowing an easy coupling with the 3D NK code in the following phases of the work.

Moreover, two relevant TH features characterizing the LMFR operation have been studied: thermal stratification within large plena and liquid metal free surface motion. This work represents the preliminary validation stage of the modelling, involving R5-3D standalone calculation. For this purpose, a TH nodalization has been developed at DIAEE, based on a three-dimensional (3D) model of the Reactor Vessel (RV) and a one-dimensional (1D) scheme of the reactor core and of the primary and secondary Heat Transport Systems (HTSs). The 1D modelling simulates one by one the core assemblies, allowing an easy coupling with a 3D NK code, and each of the three HTSs, to account for possible asymmetric operations. For the scope of the present paper, the total core power is imposed as boundary condition (i.e., NK calculation is not performed).

\section{Description of FFTF}

FFTF was a loop-type SFR prototype with a nominal thermal power of $400 \mathrm{MW}$. Figure 1 shows the plant layout, consisting in the RV and the primary and secondary HTSs. Low-pressure liquid sodium removed heat generated within the core and fed three primary HTS loops. Each one was equipped with an Intermediate Heat Exchanger (IHX), foreseen to separate activated liquid metal in the primary loops from nonradioactive sodium within the secondary loops. FFTF was not conceived to generate electricity, thus an overall number of twelve air Dump Heat Exchangers (DHXs) (four per each secondary HTS loop) discharged thermal power to the environment.

The RV was a cylindrical vessel with a bottom torospherical head, $13 \mathrm{~m}$ high and $6.3 \mathrm{~m}$ outside diameter. Sodium, coming from the primary cold legs, entered the inlet plenum through three deflector elbows, which guided cold fluid to the bottom, enhancing mixing. The primary coolant was drawn up into the core support structure, passing across dedicated holes (see arrows in Figure 1, representing the flow path inside the RV). Within the core support structure, the core basket was foreseen to allocate assemblies' receptacles. The primary mass flow rate (MFR) entered this region, passing through dedicated openings realized on the lateral walls of the core basket. Most of 
Nuclear Engineering and Design, 383 (2021) 111405, https://doi.org/10.1016/i.nucengdes.2021.111405

the sodium was drawn within the assemblies to remove core power. The remaining sodium was divided between the core bypass and the bypass vessel cooling. The vessel cooling flow rate was redirected to the bottom of the core basket (see arrows in Figure 1) and drawn in the peripheral region of the core support structure through twelve sloped holes. Three bypass coolant pipes led sodium from the peripheral volume of the core support structure to the annular riser between the vessel thermal liner and the RV walls. Sodium moved upward, cooling $\mathrm{RV}$ walls, and was discharged at the top of the outlet plenum, where mixed with the coolant flowing through the core assemblies, reflector, radial shield, and core bypass. The outlet plenum was bounded with argon cover gas to reduce possibility for sodium contacting air. Several devices were located within the outlet plenum (e.g., control rod drivelines, in-vessel handling machine, instrument tree and low-level flux monitoring system), but these details have been not provided in the benchmark specification (Sumner, 2018).

The hot sodium flow rate was divided in three primary loops (only one represented in Figure 1). Hot leg ran from the RV to the primary pump and then to the IHX, and cold leg returned to the RV inlet plenum. The equalizing lines, one per loop, connected RV cover gas with primary pumps. They were foreseen to equalize argon pressure within the circulators with RV cover gas pressure. During normal operation, the difference of sodium level between $\mathrm{RV}$ and equalizing lines was representative of the pressure losses between these two components.

The IHX was a vertical counterflow shell and tube type (Sumner, 2018). Primary sodium entered the component laterally and flowed downward through the shell side, transferring heat to the secondary HTS. Cold sodium was collected at the bottom of the active heat transfer region and discharged in the primary cold leg. The secondary coolant ran from the secondary pump, entered at the top of the IHX and flowed downward through the central downcomer toward the bottom head. It was distributed among the tubes and moved upward to the upper head. Here, the secondary sodium exited the IHX and was drawn to the DHXs. The IHXs are characterized by 1540 tubes (per heat exchanger) and by $4.2 \mathrm{~m}$ of active height.

The reactor core allocated an overall number of 199 hexagonal assemblies. The loading pattern adopted in the analyzed test was composed of 8 different types of assemblies (Sumner, 2018): Driver Fuel Assemblies (DFAs), In Core Shim Assembly (ICSA), reflector assemblies, Control Rods (CRs), Safety Rods (SRs), Material Open Test Assembly (MOTA), Fracture Mechanics Assembly (FMA) and Gas Expansion Modules (GEMs). The active core consisted of 80 DFAs located in the first six rows (orange assemblies in Figure 1 - refer to the online version of the paper). Each one was composed of 217 mixed oxide fuel pins, with an active length of $914 \mathrm{~mm}$ (red region in Figure 1 - refer to the online version of the paper). Two locations in row 6 were occupied by the MOTA and the ICSA: the first one was an instrumented open test assembly and the second one was a non-fueled assembly where stainless steel pins substituted for the fuel pins. The reactivity was actively controlled by three SRs (row 3 ) and six CRs (row 5). The active region was surrounded by the reflector assemblies, from row 7 to row 9 (brown assemblies in Figure 1 - refer to the online version of the paper). In row 7, one location was occupied by the FMA (to continue irradiation of FFTF archives and surveillance program specimens) and nine locations were foreseen for GEMs. The GEM was a passive safety device essentially composed of a $3.658 \mathrm{~m}$ long pipe, sealed at the top and open at the bottom. It was filled with sodium and cover gas (argon) (Wootan et al., 2017a). During normal operation, the sodium head and the primary pump discharge pressure compressed the gas volume, fixing the sodium free level above the Top of Active Fuel (TAF). The loss of primary flow, and the consequent pressure decrease at the core inlet (i.e., GEM bottom) caused the gas to expand within these assemblies. The gas expansion forced sodium level to reduce below the Bottom of Active Fuel (BAF), determining passive negative reactivity feedback. Indeed, GEMs were located just beyond the DFAs (row 7) and the decrease of the amount of sodium surrounding the core led to higher radial neutron leakage, corresponding to a negative reactivity insertion (Nguyen, 1990). The region between row 9 and core barrel is occupied by the shield plates and the core 
restraint system, designed to allow core radial expansion during power transients, resulting in overall negative reactivity feedback.

Since FFTF was a prototype test facility for SFRs, it was extensively instrumented (Sumner, 2018; Wootan et al., $2017 \mathrm{~b})$. For the scope of the present paper, thermal-hydraulic acquisitions are summarized. Several slow response thermocouples (TCS) were utilized to measure core outlet temperature. In addition, fast response TC packages were installed above selected DFAs, called Proximity Instrumented Open Test Assemblies (PIOTAs). A duct, instrumented with multiple TCs, was installed at the top of the PIOTAs. The fast acquisition of the core outlet temperature is essential for transient analysis. In the selected experiment, two PIOTAs were installed in rows 2 and 6 . Accuracy of these TCs was not declared by the benchmark organizers. Outside RV, sodium temperature was acquired in the hot and cold leg of each primary and secondary loop. On the secondary side, TCs were installed at the DHX outlets. Accuracy of these TCs was estimated to be $\pm 1.6 \mathrm{~K}$. The sodium flow rate was measured in the cold leg of each primary and secondary loop with permanent magnet flow meters. Above $2.27 \mathrm{~m}^{3} / \mathrm{min}$ the measurement accuracy was estimated to be $\pm 2.8 \%$, and below $1.14 \mathrm{~m}^{3} / \mathrm{min}$ was estimated within $\pm 0.114 \mathrm{~m}^{3} / \mathrm{min}$.

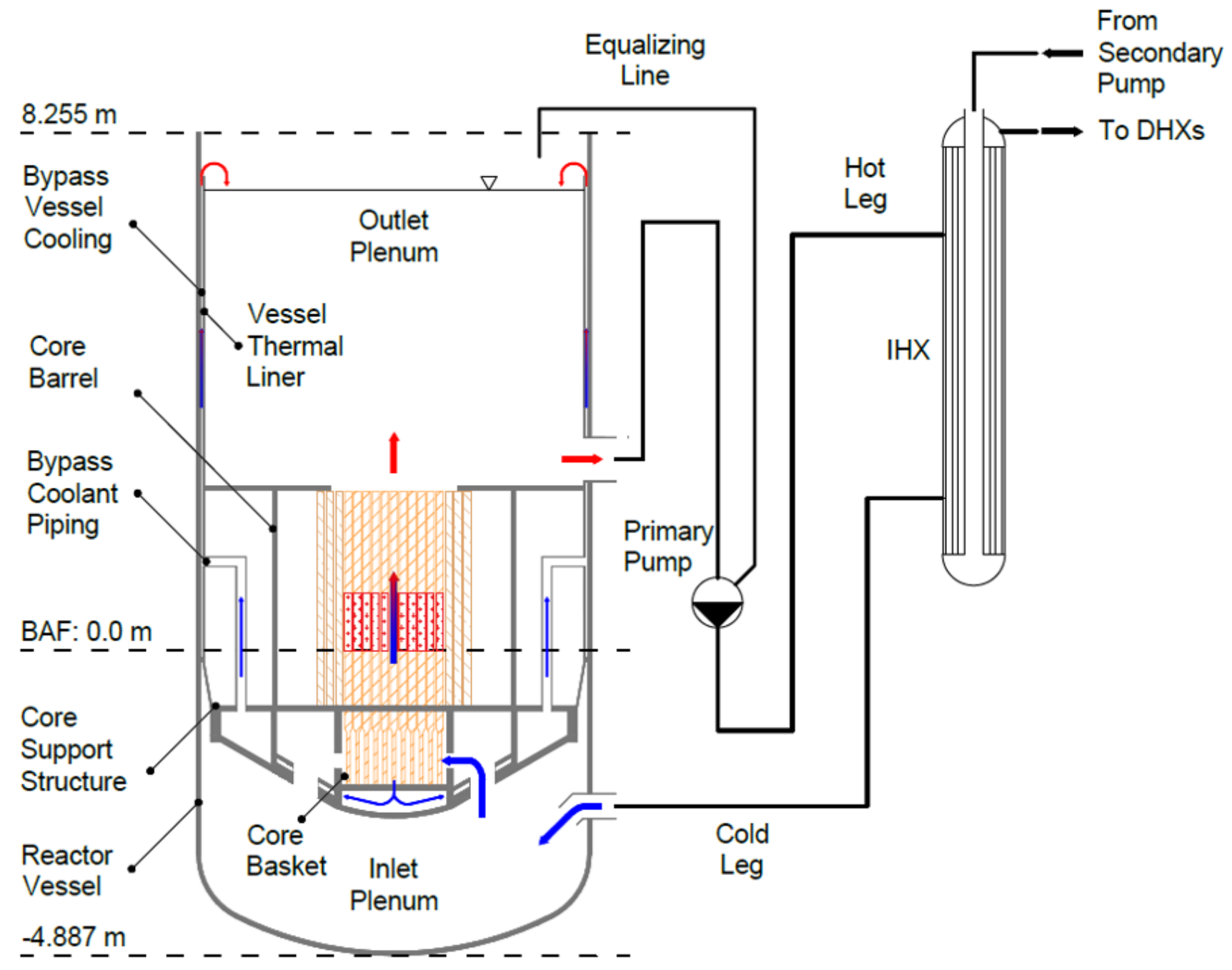

Figure 1. FFTF plant layout 


\section{LOFWOS Test \#13}

LOFWOS Test \#13 was performed in 1986 as part of the passive safety testing program, involved in the verification of safety margin of FFTF, as an LMFR demonstrator, under an unprotected loss of flow condition. Before the initialization, the reactor was kept at around $50 \%$ of the nominal power and $100 \%$ of the nominal primary flow rate for seven and a half hours to reach steady-state conditions. Core inlet temperature was maintained about $44 \mathrm{~K}$ lower than nominal value to ensure peak fuel temperature below safety limits throughout the test (Sumner, 2018).

Approximately one minute before the beginning of the transient, DHXs fan speed was reduced, causing the temperature increase in the secondary HTS cold legs (Sumner, 2018). This operation was carried out to keep a relatively constant temperature at the core inlet over the whole test (Sumner et al., 2020). The secondary pumps speed was kept constant throughout the experiment.

The initial conditions of the LOFWOS Test \#13 are summarized in Table 1.

Table 1. LOFWOS Test \#13: initial conditions (Sumner, 2018)

\begin{tabular}{lcc}
\hline Parameter & Units & Value \\
\hline Total power & $\mathrm{MW}_{\text {th }}$ & 199.2 \\
Core inlet temperature & $\mathrm{K}$ & 590.4 \\
Total primary MFR & $\mathrm{kg} / \mathrm{s}$ & 2202.24 \\
RV Sodium level $^{1}$ & $\mathrm{~m}$ & 7.341 \\
GEM sodium level $^{1}$ & $\mathrm{~m}$ & 1.213 \\
Average DHX outlet temperature $^{2}$ & $\mathrm{~K}$ & 574.6 \\
Total secondary MFR $^{1}$ Elevation relative to the BAF & $\mathrm{kg} / \mathrm{s}$ & 2202.2 \\
\hline${ }^{2}$ Before fan speed decrease. & &
\end{tabular}

The test started when the three primary pumps were simultaneously tripped. The plant protection system was modified to avoid the active scram and the primary pony motors were turned off, ensuring the natural circulation establishment. The primary flow coastdown was governed by the kinetic energy stored in the inertia of the pumps. The speed of the three primary pumps throughout the experiment has been provided as boundary condition to the benchmark participants (Sumner, 2018). The prompt primary flow decrease caused the powerto-flow ratio to rise in the first seconds of the transient, resulting in the quick temperature increase at the core outlet. This phenomenon, plus the core inlet pressure decrease (i.e., GEM level drop), generated the essential reactivity feedbacks to reduce core power to the decay heat value once the natural circulation was established.

Five Phenomenological Windows (PhWs) can be identified in the transient. Table 2 summarizes the main events occurring in each PhW. 
Nuclear Engineering and Design, 383 (2021) 111405, https://doi.org/10.1016/i.nucengdes.2021.111405

Table 2. LOFWOS Test \#13: PhWs definition

\begin{tabular}{|c|c|c|}
\hline PhW & Time interval (s) & Description \\
\hline 1 & $-120-0$ & DHX fan speed decrease and temperature rise in secondary cold legs \\
\hline 2 & $0-9$ & Power-to-flow ratio increase; first peak temperature at the core outlet \\
\hline 3 & $9-25$ & $\begin{array}{l}\text { Power coastdown governed by negative reactivity feedbacks; effective } \\
\text { core cooling by pumps inertia }\end{array}$ \\
\hline 4 & $25-100$ & $\begin{array}{l}\text { GEM level below BAF; primary system energy increase and core outlet } \\
\text { temperature maximum peak }\end{array}$ \\
\hline 5 & $\begin{array}{l}100-\text { End of } \\
\text { transient }\end{array}$ & Long-term cooling in natural circulation \\
\hline
\end{tabular}

\section{RELAP5-3D modelling}

\subsection{The code and state of the art for liquid metal applications}

The RELAP5-3D ${ }^{\odot}$ (R5-3D) is the latest version in the RELAP5 code series, developed at the Idaho National Laboratory. The code was originally developed for transient analysis in light water reactors (e.g., loss of coolant, anticipated transients without scram, loss of feedwater and station blackout). Beside its primary applications, R5-3D is a highly generic code whose applicability was enlarged to a wide range of thermal-hydraulic applications, including both nuclear and non-nuclear systems. Moreover, several enhancements were implemented, that distinguish R5-3D from the previous versions of the code. The most relevant improvements are the addition of new working fluids, enlarging applicability of the code to LM-cooled system (e.g., sodium, lead and lead alloys) and more, the fully integrated multi-dimensional (MULTID) modelling capability, originally developed for MULTID hydrodynamic features of characteristic reactor components (i.e., core, downcomer and steam generator), and the kinetic modelling capability (The RELAP5-3D ${ }^{\odot}$ Code Development Team, 2015a).

In the past years, the Horizon 2020 SESAME (thermal-hydraulics Simulation and Experiment for the Safety Assessment of Metal cooled reactor) project offered a unique opportunity to enhance knowledge of LMFR thermal-hydraulics and for the assessment of computer codes in the simulation of such systems (Reolofs, 2019). In this framework, three benchmark exercises were performed to compare and validate advanced numerical approaches for design and safety assessment of LMFRs. The validation benchmarks involved a Lead-Bismuth Eutectic alloy (LBE) loop facility (NACIE-UP test facility) (Forgione et al., 2019), a pool-type LBE facility (CIRCE experimental facility) (Lorusso et al., 2021), and the pool-type SFR Phénix (Narcisi et al., 2019a). Predictive capabilities of R5-3D and other System Thermal-Hydraulic (STH) codes (including STH/CFD coupling methodologies) were compared with experimental data, showing hopeful ability of the codes to simulate a wide variety of conditions related to both normal and abnormal operations of LM systems.

The R5-3D ability to reproduce loss of flow scenario in LM systems were extensively investigated by Davis (2006), Castelliti and Hamidouche (2017), Narcisi et al. (2019b; 2019c) and Lorusso et al. (2019a). In the activities presented by Narcisi et al. (2019b; 2019c) and Lorusso et al. (2019a), code's capabilities were demonstrated by comparing simulation outcomes with experimental data obtained in two different configurations of the CIRCE facility. The high-quality predictions were kept changing relevant parameters such as the steam generator layout and the distance between heat source and heat sink centers of gravity. Unusual modelling approaches were also investigated, using the R5-3D as a subchannel analysis code (Memmott et al., 2010; Narcisi et al., 2019c) and the MULTID component to reproduce LM large tanks (Narcisi et al., 2019b; 2019c; 2020a). 
Nuclear Engineering and Design, 383 (2021) 111405, https://doi.org/10.1016/i.nucengdes.2021.111405

State of the art has been comprehensively studied by the authors. The main outcomes and the modelling best practice guidelines gathered in literature have been applied for the development of a detailed FFTF thermalhydraulic model.

\subsection{FFTF thermal-hydraulic nodalization}

The FFTF nodalization scheme developed at DIAEE is presented in Figure 2, respecting the actual relevant elevations. It basically consists in two macro-regions: the first one is the three-dimensional meshing of the reactor vessel and the second one is the one-dimensional modelling of the HTSs and the core assemblies.

Four MULTID components simulate the RV. Cylindrical geometry is used $(r, \theta, z)$, where the dimensions of the 3D array are selected based on actual symmetries and sizes of the RV and the internals, and on modelling choices summarized in this section. Six azimuthal intervals ( $\theta$-coordinate) are used ( $60^{\circ}$ each one) and kept for all the MULTID components, based on the symmetry of the equipment installed within the RV. Concerning the radial discretization ( $r$-coordinate), it is chosen based on internals structures (depicted with red lines in Figure 2 - refer to the online version of the paper) and expected thermal-hydraulic features. The MULTID component 300 simulates the inlet plenum. It is basically an empty volume (internal structures was not present). Almost uniform thermal-hydraulic conditions are expected for the steady-state operation and during the LOFWOS Test \#13. For this reason, a coarse $r$-meshing is used, consisting in three radial intervals: the first one accounts for the volume below the core region and the other two reproduce the outer annular area. The MULTID component 301 simulates the core basket and the core bypass (the gap between the assemblies). From a thermal-hydraulic point of view, the modelling of this component has a crucial effect on the transient analysis, since it influences the core gagging scheme, providing the connections between assemblies and core basket, and the heat exchange between assemblies and core bypass, which assumes relevant effects during the decay heat removal under natural circulation. The magnitude of this latter phenomenon was recognized by Del Nevo and Martelli (2016) and by Liu and $\mathrm{Hu}$ (2020). For this reason, a detailed r-meshing is developed for component 301 consisting in three radial sections: the inner one surrounding the first four rows of the core, the intermediate one enveloping row 5 and 6, and the external one including rows from 7 to 9. Concerning the MULTID component 302, the rmeshing follows the arrangement of the internal structures. The component simulates the annular region between the core and the RV's walls. It is divided in three radial meshes. The first one goes from the core outer boundary to the core barrel: it accounts at the bottom for the inlet region of the core support structure and, at the top, for the sodium flow path between the shield plates. The second radial mesh goes from the core barrel to the vessel thermal liner, which separates the RV internal volumes from the bypass vessel cooling. It includes the upper part of the RV inlet plenum, the external region of the core support structure and the annular volume outside the core barrel. The third mesh is the external one and reproduces the thin volume between the vessel thermal liner and the RV's walls, simulating the bypass vessel cooling. The MULTID modelling is completed with component 303, which models the RV outlet plenum. A prominent temperature gradient is expected in the $r$ coordinate, especially in the volume above the core region. For this reason, the radial discretization assumed for components 301 and 302 is still adopted for this component. Six radial meshes are foreseen: the inner three simulate the region above component 301 and the outside three reproduce the volume above component 302 .

Concerning the axial discretization (z-coordinate), it is guided by the relevant elevations of the components (RV and internal structures) and is developed with the sliced modelling approach. This methodology consists in the adoption of the same mesh length (or submultiple) for the vertical control volumes belonging to different nodalization regions and positioned at the same axial level. This technique improves the capability of the code to reproduce natural circulation. When adopted, fluid properties are evaluated at the same axial elevations for all the nodalization regions, resulting in a proper evaluation of the natural circulation driving force and avoiding an error source on the simulation outcomes (Mascari et al., 2011). For the present model, the axial discretization 
Nuclear Engineering and Design, 383 (2021) 111405, https://doi.org/10.1016/i.nucengdes.2021.111405

is developed in order to maintain an average axial length of the cells in the range of $100-200 \mathrm{~mm}$. The most detailed discretization is foreseen in the zones where a prominent temperature gradient is expected (e.g., core region and heat exchangers). A mesh sensitivity analysis has been performed for the axial discretization of component 303 and is described in section 5.3.

To account for the volume occupied by internal structures and core assemblies, and to allow the correct evaluation of the lower plenum inventory, calibrated volume factors are considered for the MULTID components. They are evaluated for each computational cell as the ratio between the actual free volume and the mesh original volume. With analogous approach, junction factors are evaluated to account for actual flow area and to exclude control volumes from the computational domain.

Above component 303, the RV top head (including the sodium free level and the cover gas plenum) and the bypass vessel cooling upper part are simulated with 1D pipe components, respectively 315 and 316 . At the top, pipe 315 is connected to a time-dependent volume which set argon conditions (i.e., cover gas pressure) throughout the test. The bypass vessel cooling flow rate is allowed by the pipe components from 341 to 346, reproducing the 12 sloped holes, and the pipes 331, 333 and 335, simulating the bypass coolant piping.

Several heat structures are foreseen to simulate the heat exchange between adjacent regions within the RV and to account for the material inventories. Moreover, heat losses through the RV's walls are simulated, imposing constant heat transfer coefficient $(\mathrm{HTC})$ on the outside surface $\left(8 \mathrm{~W} / \mathrm{m}^{2} \mathrm{~K}\right)$ and constant external temperature (303 K).

The HTSs consist of three primary loops and three secondary loops. The circuits are individually modelled. Figure 2 depicts a single loop for the primary and secondary HTSs, representative of the three circuits. The HTS modelling is developed with one-dimensional components (e.g., pipe, branch, and pump). The primary loop nodalization accounts for the hot leg, the pumping system (including the pump skirt, the pump component, and the pump discharge), the IHX primary side (composed of the distribution manifold, the IHX shell side and the annular exit region) and the cold leg. Concerning the primary pump, it is simulated with a pump component, whose homologous curves are derived from data provided in the benchmark specifications (Sumner, 2018). Pipeline thermal insulation is simulated by means of HSs, imposing the boundary conditions mentioned above.

The secondary loop modelling goes from the outlet to the inlet of the dump heat exchangers. The DHXs are not modelled and are simulated with two time-dependent volumes per each heat exchanger: the first one set DHX outlet temperature and the second one imposes DHX inlet pressure. The secondary loop model includes the cold leg, the secondary pump system, the secondary side of the IHX and the hot leg. In this case, the operation of the secondary pump is simulated with a time-dependent junction, which set the secondary flow rate. In the IHX modelling, the tube bundle is simulated with two ascending parallel pipe components, each one accounting for half bundle. The IHX model is completed with the central downcomer and the lower and upper head, modelled with pipe components. Several heat structures simulate the heat exchange involved in the IHXs as well as the heat losses towards the environment, assuming the boundary conditions presented above. Furthermore, HSs are used to account for IHX steel inventory. Concerning the pressure drops, standard R5-3D wall friction correlations are used for the HTSs and local pressure loss (k-loss) coefficients are evaluated on the basis of the actual geometries. 


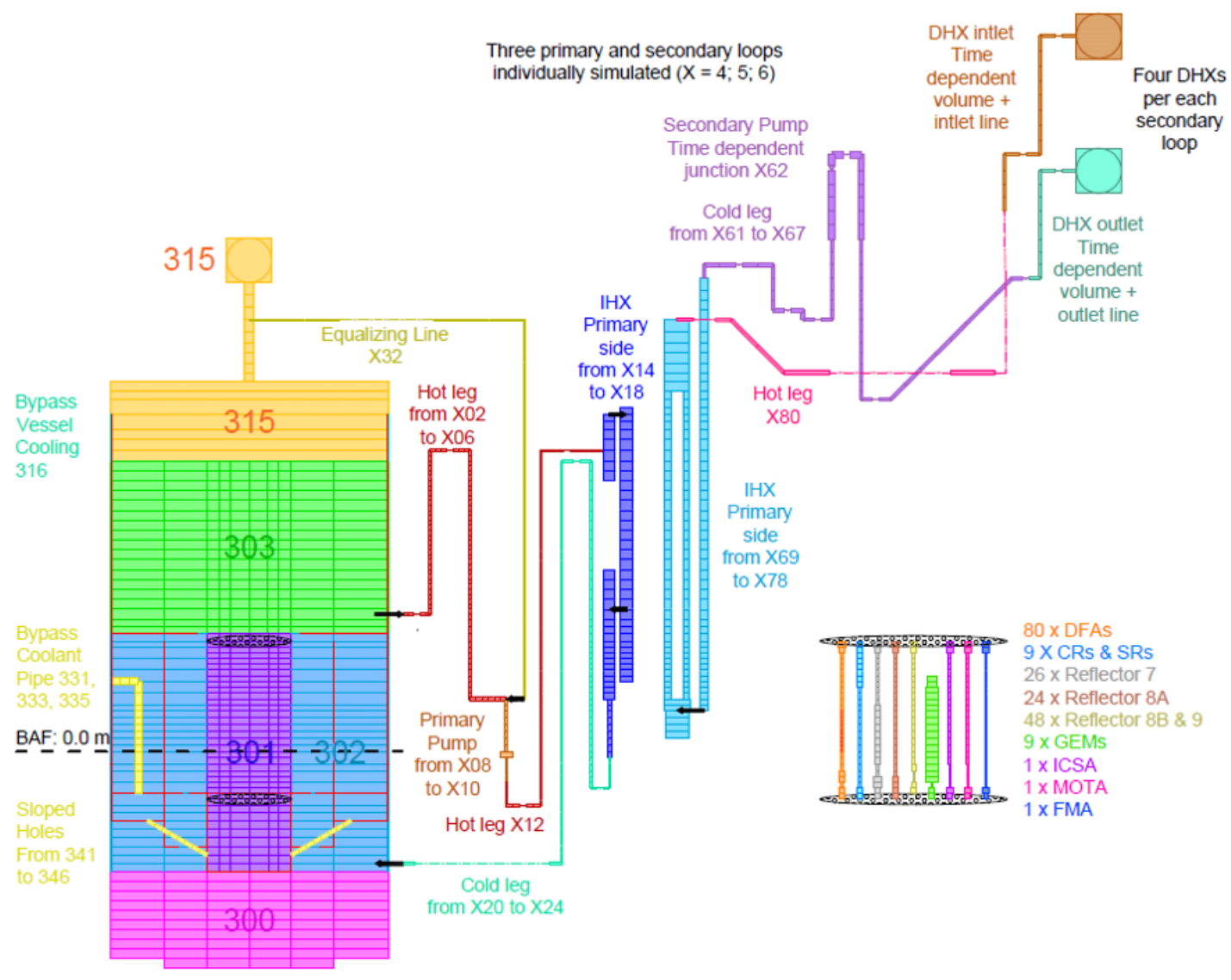

Figure 2. Nodalization scheme

Concerning the reactor core modelling, the assembly-by-assembly approach is adopted, allowing an easy coupling with a 3D NK code in the future phases of the activity. Hence, a single pipe component is associated to each assembly, for a total of 199 components. The actual reactor core arrangement is kept by a proper thermalhydraulic coupling (i.e., heat structures and hydraulic junctions) between assemblies and MULTID component 301. The geometrical features of each equivalent pipe are differentiated according to the assembly type (see Figure 2). Axial discretization is consistent with the assembly design (Sumner, 2018) as well as with the sliced modelling approach. Twenty-six control volumes compose each equivalent pipe, except for the ones related to reflectors 8B and 9 (twenty-five cells) and GEMs (twenty cells). Indeed, reflectors 8B and 9 have shorter inlet nozzle whereas GEMs present a lower height, ending well below the DFA top (see Figure 2). Concerning the pressure drops, specific correlations are adopted for the pressure losses evaluation where a wire-wrapped hexagonal rod bundle is present (i.e., DFAs and CRs). For this purpose, R5-3D allows to modify the standard wall friction correlation to account for a more suitable correlation. The wall friction model implemented in the code is summarized in Table 3, where $f$ stands for the friction factor, $R$ is the surface roughness, $D_{h}$ is the hydraulic diameter, and subscripts $L$ and $T$ represent laminar and turbulent regimes, respectively. In Eq. (1), $\phi$ is a shape factor that allows the user to account for geometries different than a circular tube. Regarding the turbulent friction factor, in addition to the default model (Zigrang and Sylvester (1985) approximation to the Colebrook (1939) correlation - Eq. (3)), the code provides an alternative formulation (Eq. (4)) in which parameters $A, B$, and $C$ can be properly defined by the user for each control volume. Finally, the friction factor in the transition region between laminar and turbulent flow is calculated by R5-3D by interpolating between laminar value at $R e$ equal to $2200\left(f_{L, 2200}\right)$ and turbulent value at Re equal to $3000\left(f_{T, 3000}\right)$, obtaining Eq. (2). Note that R5-3D assumes that 
the transition between laminar to turbulent regime occurs between $R e$ of 2200 and 3000 . The adopted approach is to calculate $\phi, A, B$, and $C$ to match a more appropriate correlation for the selected geometry: in this case the Cheng and Todreas (1986) correlation, developed for the frictional pressure drop of wire-wrapped rod bundles.

Nevertheless, Davis (2006) identified some issues related to the transition region when this methodology is used. The reason is the impossibility to change in R5-3D the range of $R e$ in which the transition occurs. As matter of fact, Cheng and Todreas (1986) derived empirical correlations to obtain this range of $R e$, depending, among other parameters, on the pitch-to-diameter ratio (around 1.24 in DFAs of FFTF). According to these correlations, the transition region in the FFTF DFAs occurs between 776 and 14788, considerably different from the R5-3D values. Figure 3 shows the friction factor for the DFA wire-wrapped bundle vs. Re, comparing R5-3D models with Cheng and Todreas (1986) (C\&T in Figure 3). Two different R5-3D models are presented. The first one, namely R5-3D (blue line - refer to the online version of the paper), is obtained calculating $\phi, A, B$, and $C$ to properly match Cheng \& Todreas (1986) correlation in laminar and turbulent regimes. As expected, the friction factor is well reproduced below 776 and above 14788, but relevant discrepancies are observed in the transition regime (especially between 776 and 3000), where R5-3D model underestimates the friction factor (the maximum error is $31 \%$ at $R e$ of 2200). Such disagreement could be neglected if flow regime does not drop in this $R e$ region during the LOFWOS transient. However, Figure 4 shows that after the transition event, Re assumes values between 1500 and 3000 through the PIOTAs. Such result indicates that the friction factor model needs to be improved in the transition regime.

Table 3. R5-3D wall friction model (The RELAP5-3DC Code Development Team, 2015b)

\begin{tabular}{lcc}
\hline Regime & Correlation & Eq. \\
\hline Laminar $(\operatorname{Re}<2200)$ & $f_{L}=\frac{64}{\operatorname{Re} \varnothing}$ & (1) \\
Transition $(2200<\operatorname{Re}<3000)$ & $f=\left(3.75-\frac{8250}{R e}\right)\left(f_{T, 3000}-f_{L, 2200}\right)+f_{L, 2200}$ \\
& $\frac{1}{\sqrt{f_{T}}}=-2 \log _{10}\left\{\frac{R}{3.7 D_{h}}+\frac{2.51}{R e}\left[1.14-2 \log _{10}\left(\frac{R}{D_{h}}+\frac{21.25}{R e^{0.9}}\right)\right]\right\}$ \\
Turbulent $(\operatorname{Re}>3000)$ & $f_{T}=A+B R e^{-C}$ & (3)
\end{tabular}

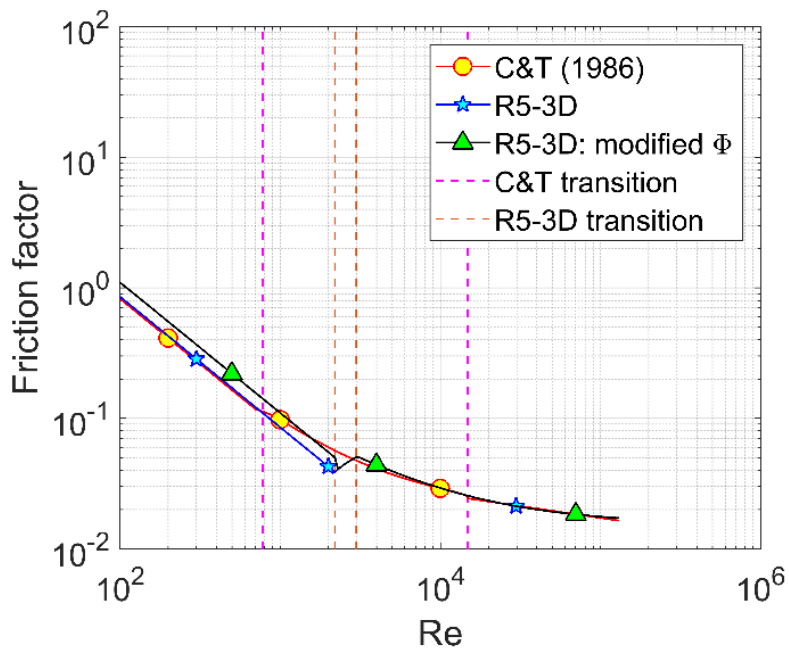

Figure 3. Friction factor vs Re for DFA wire-wrapped bundle: comparison between Cheng and Todreas correlation and different R5-3D modelling approaches.

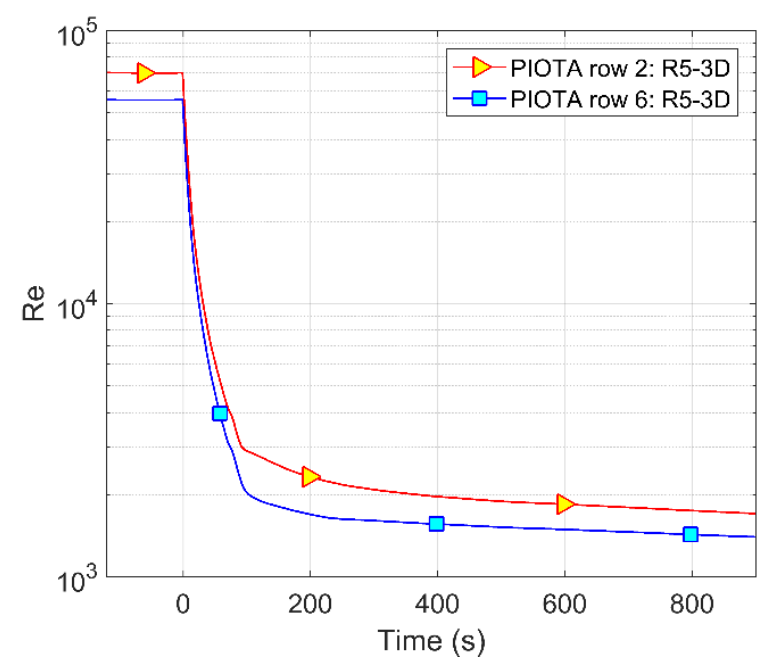

Figure 4. LOFWOS test: Re through PIOTAs wire-wrapped bundle 
Nuclear Engineering and Design, 383 (2021) 111405, https://doi.org/10.1016/i.nucengdes.2021.111405

The correction adopted in the FFTF modelling is to calibrate $\phi$ to minimize the error in the range of Re between 1500 and 3000. The obtained trend is presented in Figure 3, namely R5-3D: modified $\phi$. Such adjustment determines a systematic error in the laminar regime. Nevertheless, this discrepancy is reasonable since laminar flow is not expected through the DFAs over the whole transient. On the other hand, the root mean squared relative error in the considered Re range is reduced from 25\% to $10 \%$ (comparable with the uncertainty range of Cheng and Todreas correlation). Clearly, the proposed modification does not influence the friction factor for $R e$ higher than 3000, keeping a satisfactory agreement with Cheng and Todreas (1986) formulation.

Furthermore, assembly's orifices are calibrated based on mass flow rate data and overall dynamic pressure drops in the nominal steady-state. Geometrical details of the orifices have not been provided in the benchmark specifications, thus constant k-loss coefficients are calibrated with iterative calculations based on mass flow and pressure drop data provided in the benchmark specifications. Several heat structures are developed, accomplishing different functions in each assembly. They simulate the internal power source (provided as boundary condition with a power vs. time table) as well as the heat transfer within the assembly. Moreover, other heat structures reproduce heat exchange between assembly and core bypass and account for the material inventories (e.g., fuel, absorber, steel and Inconel).

Regarding the HTC evaluation, standard R5-3D liquid metal correlations are adopted: Seban and Shimazaki (1951) correlation for non-bundle and Westinghouse correlation (Kazimi and Carelli, 1976) for bundle geometries. In the IHXs, tube bundle is characterized by a high pitch-to-diameter ratio (nearly 1.5), thus Graber-Rieger correlation modified by Sha and Launder (1979) is more appropriate. The procedure to implement such correlation in the input deck is described by Narcisi et al. (2020a).

\section{Simulation activity}

The computational activity has been performed using RELAP5-3D ${ }^{\odot}$ ver. 4.3.4. The present section summarizes the main outcomes of the analysis. Section 5.1 characterizes the nodalization scheme against FFTF steady-state operative data. Results of the steady-state calculation are then used as initial conditions of the experiment. Section 5.2 reports the comparison between experimental data (Sumner et al., 2020) and transient simulation, discussing the main outcomes of the analysis. Finally, section 5.3 and 5.4 analyse two peculiarities that characterize LMFRs operations: thermal stratification within large plena and sodium free surface motion.

\subsection{Steady-state analysis}

Initial conditions presented in section 3 have been used for the steady-state calculation. In addition to the data summarized in Table 1, primary pumps speed and RV cover gas pressure have been provided in the benchmark specifications, as well as the mass flow and power distributions in the core assemblies. The reference gagging scheme divides core assemblies in sixteen Flow Zones (FZs). The mass flow associated to each FZ was evaluated with hydraulic test preliminary performed on the correspondent assembly. The sixteen FZs are defined in Table 4. The first seven are related to the DFAs and the PIOTAs. Fuel assemblies are differentiated in four groups (i.e., 3.1, 3.2, 4.1 and 4.2), according to the initial enrichment. Two series are identified: the first one (named 3) with minor enrichment and the second one (named 4) with major. In addition, for both series, the fissile content rises from inner (3.2 and 4.2) to outer (3.1 and 4.1) core. For this seven FZs, the pressure losses characterization has also been provided. Furthermore, power data have been given detailed assembly per assembly following the pre-transient benchmark specifications (Sumner, 2018).

Table 5 summarizes the main relevant sodium flow rates through the primary system, comparing simulation results with data provided in the benchmark specifications. The total primary flow rate, as well as the sodium 
MFR through the primary loops, agrees with the benchmark specifications. As presented in Figure 1, the greater portion of the primary flow rate is drawn in the core assemblies, achieving power removal. Table 5 shows a small overprediction of the total core assembly flow rate, even if the error can be considered negligible. The rest of the primary flow rate is divided between core bypass, bypass vessel cooling, and the leakages across the core support structure. The R5-3D flow distribution in the assemblies is compared with the reference values. Per each FZ, Table 5 reports the maximum discrepancy with respect to the provided data. The maximum error is observed through an assembly belonging to the FZ 13 (i.e., reflector type 2, row 7). It is worth emphasising that the maximum discrepancy is limited to $1.7 \%$ of the rated assumption in the corresponding FZ. This value is reduced to $1.13 \%$, considering only the DFAs.

Table 4. Flow zones definition

\begin{tabular}{lll}
\hline Flow zone & Description & $\mathrm{N}^{\circ}$ of Assembly \\
\hline 1 & DFA 3.2 & 22 \\
2 & DFA 3.1, row 5 & 12 \\
3 & DFA 3.1, row 6 & 22 \\
4 & DFA 4.1 and 4.2, rows 2-5 & 12 \\
5 & DFA 4.1, row 6 & 5 \\
6 & DFA 3.2, with PIOTA row 2 & 4 \\
7 & DFA 3.1, with PIOTA row 6 & 3 \\
8 & MOTA & 1 \\
9 & ICSA & 1 \\
10 & CR and SR & 9 \\
11 & FMA & 1 \\
12 & Reflector type 1, row 7 & 11 \\
13 & Reflector type 2, row 7 & 15 \\
14 & Reflector, row 8a & 24 \\
15 & Reflector, row 8b & 18 \\
16 & Reflector, row 9 & 30 \\
\hline
\end{tabular}


Nuclear Engineering and Design, 383 (2021) 111405, https://doi.org/10.1016/i.nucengdes.2021.111405

Table 5. Steady-state conditions: mass flow rate $(\mathrm{kg} / \mathrm{s})$

\begin{tabular}{lccc}
\hline Parameter & Exp. & R5-3D & Error \\
\hline Total primary & 2202.24 & 2202.25 & $\sim 0.00 \%$ \\
HTS & & & \\
Primary loop 1 & 736.91 & 736.92 & $\sim 0.00 \%$ \\
Primary loop 2 & 735.68 & 735.68 & $\sim 0.00 \%$ \\
Primary loop 3 & 729.65 & 729.65 & $\sim 0.00 \%$ \\
Through all & 1988.42 & 2001.42 & $0.65 \%$ \\
assemblies & & & \\
FZ 1 & $25.39^{1}$ & $25.63^{2}$ & $0.93 \%^{2}$ \\
FZ 2 & $24.14^{1}$ & $24.38^{2}$ & $1.00 \%^{2}$ \\
FZ 3 & $20.82^{1}$ & $20.87^{2}$ & $0.25 \%^{2}$ \\
FZ 4 & $25.39^{1}$ & $25.67^{2}$ & $1.13 \%^{2}$ \\
FZ 5 & $19.97^{1}$ & $20.04^{2}$ & $0.36 \%^{2}$ \\
FZ 6 & $24.82^{1}$ & $24.92^{2}$ & $0.41 \%$ \\
FZ 7 & $20.50^{1}$ & $20.49^{2}$ & $-0.04 \%$ \\
FZ 8 & 1.79 & 1.79 & $0.14 \%$ \\
FZ 9 & 2.04 & 2.03 & $-0.01 \%$ \\
FZ 10 & $4.55^{1}$ & $4.53^{2}$ & $-0.40 \%^{2}$ \\
FZ 11 & 0.65 & 0.64 & $-1.37 \%$ \\
FZ 12 & $1.79^{1}$ & $1.79^{2}$ & $0.21 \%^{2}$ \\
FZ 13 & $0.89^{1}$ & $0.91^{2}$ & $1.70 \%^{2}$ \\
FZ 14 & $0.73^{1}$ & $0.73^{2}$ & $0.04 \%^{2}$ \\
FZ 15 & $0.53^{1}$ & $0.54^{2}$ & $1.18 \%^{2}$ \\
FZ 16 & $0.38^{1}$ & $0.38^{2}$ & $0.18 \%^{2}$ \\
\hline 1 Each assembly within the FZ is assumed to have the same flow \\
rate & & & \\
2 The value is related to the simulated assembly & presenting the \\
higher discrepancy in the corresponding FZ &
\end{tabular}

Table 6 compares the main relevant pressure losses through the primary system with the simulation results. It is worth stressing that benchmark specifications provided primary loop pressure drops in nominal conditions (i.e., $100 \%$ core power and $100 \%$ coolant flow rate), that are quite different from initial conditions of LOFWOS Test \#13. Furthermore, also the core configuration presented some differences from the nominal set of assemblies (Sumner, 2018). Considering these changes and pondering a magnitude of conservatism in the definition of the pressure losses in the original plant documentation (amounting on the order of $10 \%$ ), in the frame of the benchmark, nominal pressure losses were reduced by $10 \%$ in the primary HTS loops and of $15 \%$ through the reactor core (accounting also for the different core configuration). Moreover, the same reference pressure drops were assumed for the three primary loops. Based on the above discussion, the low discrepancies observed between reference data and simulation outcomes can be considered satisfactory. 
Nuclear Engineering and Design, 383 (2021) 111405, https://doi.org/10.1016/i.nucengdes.2021.111405

Table 6. Steady-state conditions: pressure drops through primary system (kPa)

\begin{tabular}{lccc}
\hline Parameter & Exp. & R5-3D & Error \\
\hline DFA (FZ 1 - 7) & $623.56^{1}$ & 626.26 & $0.43 \%$ \\
Primary loop 1 (piping only) & $76.95^{2}$ & 74.90 & $-2.66 \%$ \\
Primary loop 2 (piping only) & $76.95^{2}$ & 74.65 & $-2.99 \%$ \\
Primary loop 3 (piping only) & $76.95^{2}$ & 73.44 & $-4.56 \%$ \\
IHX 1 & $52.11^{2}$ & 50.22 & $-3.63 \%$ \\
IHX 2 & $52.11^{2}$ & 50.04 & $-3.97 \%$ \\
IHX 3 & $52.11^{2}$ & 49.21 & $-5.57 \%$ \\
\hline${ }^{1} 85 \%$ of the nominal value & & & \\
$290 \%$ of the nominal value & & &
\end{tabular}

Figure 5 shows a representation of the sodium temperature within the reactor vessel, considering the cross section that includes connections with loop 3 hot leg and loop 1 cold leg. Core assemblies (e.g., DFAs, CR and reflectors) intersected by this cross section are reported in the figure. The maximum sodium temperature in the reactor core is $698 \mathrm{~K}$, reached in the DFA belonging to row 2. The typical radial distribution of the core temperature is visible in Figure 5 (refer to the online version of the paper). The coolest channel observed in the third row is a control rod, explaining the low temperature. Hot sodium exiting the core mixes just above the assemblies' outlet. Within the outlet plenum, hot sodium moves towards the cover gas, it is partially cooled and drawn to the primary HTS hot legs, descending in the lateral region of the outlet plenum. Further analysis on the buoyancy within the large plenum will be discussed in section 5.3. Primary coolant enters the hot legs with an average temperature of $662.5 \mathrm{~K}$. It passes the primary pumps and the IHXs and returns to the RV inlet plenum at around $593 \mathrm{~K}$. On the secondary HTS, sodium exits DHXs at $573.2 \mathrm{~K}$ (imposed as boundary condition), warms up in the IHXs and comes back at around $642.8 \mathrm{~K}$.

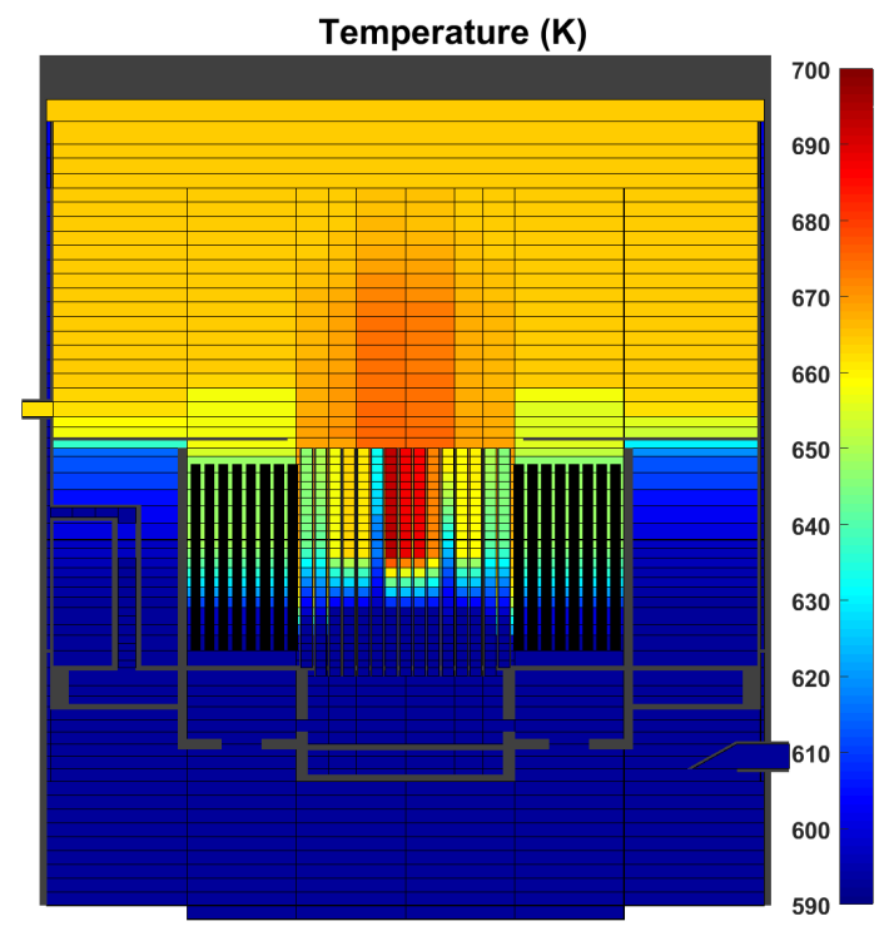

Figure 5. Steady-state conditions: sodium temperature within RV 


\subsection{LOFWOS Test \#13 transient analysis}

Steady-state result has been assumed as initial condition for the LOFWOS transient analysis. Boundary conditions presented in section 3 have been imposed. Furthermore, total core power, provided to the benchmark participants at the beginning of the post-test phase, has been used as boundary condition with a power vs. time table, in order to qualify the standalone thermal-hydraulic model. Transient analysis has been performed with a time step of $5 \times 10^{-3} \mathrm{~s}$. A time step sensitivity analysis, ranging from $5 \times 10^{-3} \mathrm{~s}$ to $5 \times 10^{-4} \mathrm{~s}$, has demonstrated the independence between this parameter and the simulation results.

The main representative figures of merit are shown in Figure 6, comparing simulation results and experiment. Experimental data are presented with their uncertainty bands (represented by the coloured bands - refer to the online version of the paper for colored pictures), where available (see section 2). Moreover, the vertical dashed lines distinguish the different PhWs.

The first PhW represents the two minutes before the transient initiating event. DHX blower speeds are reduced, and sodium temperature begins to increase at the component outlet. This latter parameter has been provided as boundary condition for the benchmark exercise. Figure 6a shows the temperature of the secondary HTS hot and cold leg (loop 3 is considered in the present analysis; the same outcomes are observed on loop 1 and 2). The experimental acquisition of the cold leg temperature is carried out downstream the secondary pump. The comparison between experiment and simulation highlights a slight overprediction of the cold leg temperature, that increases throughout the first PhW. The cold leg temperature is strongly affected by the DHX outlet temperature. Indeed, the one predicted by the calculation approaches the boundary value. Discrepancy observed at the very beginning of the test $(-120 \mathrm{~s})$ in both hot and cold leg is comparable with the TC uncertainty. After that, the computed cold leg temperature follows the increase of the boundary condition, enlarging the difference with the experimental measurement. Two phenomena could explain this discrepancy: the presence of larger thermal inertia than the value considered in the model, and the underestimation of the heat losses in the pipeline section going from DHXs to secondary pumps. Although the presence of hypothetical additional thermal inertia could explain the delay of the cold leg temperature increase, the difference between DHX outlet and cold leg temperature cannot be justified by the heat losses. Indeed, the amount of the discrepancy is not coherent with heat losses specifications provided by Sumner (2018). Further investigations are needed to understand the behaviour of the secondary cold leg.

In the primary system, an overall good agreement between experiment and simulation is observed during the first PhW, especially in the hot leg temperature and sodium mass flow rate (see Figure $6 \mathrm{~b}$ and $\mathrm{c}$ ). As described in section 2, the IHX is a counterflow heat exchanger and thus the primary outlet temperature follows the secondary inlet one. Given that primary cold leg temperature is measured just downstream the IHX, a discrepancy like the one observed at the secondary cold leg is detected. The temperatures acquired at the PIOTAs outlet are depicted in Figure 6d. As mentioned in section 2, the two PIOTAs are installed in two different positions within the reactor core (i.e., row 2 and 6 ) and thus the temperature difference between them is due to the radial power distribution. In the first PhW, although the code provides a very good estimation of the PIOTA row 6 outlet temperature, the value of the PIOTA row 2 is underpredicted of about $4.5 \mathrm{~K}$. This fact can be partially explained by the mass flow calculation, that highlights a slight disagreement in the case of PIOTA row 2, but this is not enough to justify such discrepancy. Further explanations can be related to the uncertainties of the boundary conditions. Indeed, the reference value of the flow rate derives from a hydraulic test performed before the charge and the power per each assembly, assumed as boundary condition, was generated using the PERSENT code (Sumner, 2018). These assumptions, in addition to the measurement uncertainty of the fast response TCs (not declared in the specifications) could explain the observed discrepancy. 
Nuclear Engineering and Design, 383 (2021) 111405, https://doi.org/10.1016/i.nucengdes.2021.111405

The second PhW starts with the initiator event (i.e., primary pumps trip) and concludes with the reaching of the first peak temperature in the PIOTAs. The primary pumps trip causes the sudden sodium flow rate decrease, which reduces to around $60 \%$ of the pre-transient value in $5 \mathrm{~s}$. The SCRAM command is not operated, and total core power decreases slower, governed by reactivity feedbacks. At the same time, the total power is still $73 \%$ of the pre-transient value. The increase of the power-to-flow ratio results in the abrupt temperature rise observed in Figure $6 \mathrm{~d}$. The peak value is observed after $9 \mathrm{~s}$ from the beginning of the transient, and the temperature increases of $59 \mathrm{~K}$ and $52 \mathrm{~K}$ for PIOTA row 2 and 6 , respectively. This trend is qualitatively and quantitatively well predicted by the code. Another visible effect in the second PhW is the peak temperature calculated by R5-3D in the primary cold leg (Figure 6b). However, this effect is overpredicted and anticipated by the code. The origin of the disagreement is probably related to the overestimation of the secondary cold leg temperature observed in the first PhW. The early temperature increase in the secondary cold leg causes a premature rise in temperature in the primary cold leg, which is interrupted after the pump trip and the consequent mass flow reduction. A similar effect, with a smaller magnitude, is observed at the secondary hot leg (Figure 6a).

The third PhW is governed by the power coastdown following the insertion of large negative reactivity feedbacks. Figure $6 \mathrm{c}$ shows an excellent agreement between experiment and simulation for the primary MFR decrease, still controlled by the pump inertia. At the end of the third PhW (i.e., $25 \mathrm{~s}$ after the initiating event), sodium flow rate reaches around $20 \%$ of the initial value. As the core inlet flow rate reduces, also the pressure at the core inlet decreases, allowing the gas within the GEM to expand and the sodium free level to move from above the TAF to below the BAF. This causes a larger radial neutron leakage from the core, producing huge negative reactivity feedback. The coupling effect between thermal-hydraulic and neutron-kinetic is out of the scope of the present paper. However, the characterization of the free level movement represents a relevant thermal-hydraulic parameter, preparatory for future NK/TH calculations. For this reason, section 5.4 is dedicated to this analysis.

Following the large negative reactivity feedback, and the consequent power coastdown, PIOTAs TCs experience a temperature decrease of around $25 \mathrm{~K}$, qualitatively simulated by the code even if a small underprediction is observed in PIOTA row 6 (Figure $6 \mathrm{~d}$ ). In the primary cold leg, the temperature evaluated by the code shows a fast decrease, following the MFR coastdown (Figure 6b). It is not surprising that divergences observed in the primary cold leg do not influence core temperature. As matter of fact, the discrepancy between experiment and simulation is relatively small (below $10 \mathrm{~K}$ ) and the large thermal inertia of the RV inlet plenum suppresses them. Therefore, uncertainties of the secondary system boundary conditions do not have relevant effects on the reactor core behavior.

The fourth PhW starts when the GEM level moves below the BAF and ends when the transition to natural circulation is completed. As the GEM reactivity contribution is fully inserted, the PIOTAs outlet temperature begins to increase again. PIOTA row 2 reaches the maximum value, around $80 \mathrm{~K}$ higher than the pre-transient temperature. The increase experienced in PIOTA row 6 is softer than the one of PIOTA row 2. This different behavior is partially due to the radial power distribution, but a relevant impact is provided by the heat exchange between assemblies and core bypass. Liu and $\mathrm{Hu}$ (2020) preliminary investigate this contribution. It was recognized that the position of the PIOTAs in the core array could explain the dissimilarities acquired by the fast response TCs. PIOTA row 2 is positioned in the center of the core, and thus is surrounded by other DFAs. It suggests that assemblies-to-bypass heat transfer is limited in this region of the array. On the other hand, PIOTA row 6 is installed near non-fuel assemblies (i.e., reflectors and GEMs). This means that core bypass temperature is expected to be lower than the center of the array, involving a more significant assemblies-to-bypass heat exchange. The good agreement observed in Figure $6 \mathrm{~d}$ demonstrates the capabilities of the nodalization to reproduce the effect discussed above and emphasizes the necessity to develop a detailed meshing of the core 
Nuclear Engineering and Design, 383 (2021) 111405, https://doi.org/10.1016/i.nucengdes.2021.111405

bypass accounting for assemblies-to-bypass heat transfer, which assumes importance following such a transient event.

Focusing on the secondary loop, in the fourth PhW a large temperature decrease is experienced on the hot leg. It is caused by the heat transfer coastdown across the IHX, following the primary MFR decrease (remember that secondary flow rate is kept constant throughout the test). Figure 6a shows an anticipated prediction of the hot leg temperature decrease obtained with R5-3D. In this case, thermocouples are installed just before the DHXs inlet. In accordance with what has been analysed for the secondary cold leg in the first PhW, the disagreement observed in the hot leg temperature decrease could be related to a larger thermal inertia than the one considered in the model. Additional investigations and further interactions with benchmark organizers are required to explain such discrepancies, also observed in most of the submitted blind calculations.

The fifth PhW starts with the complete transition to natural circulation and finishes at the end of the test. Figure $6 \mathrm{c}$ clearly shows this moment, occurring $100 \mathrm{~s}$ after the initiator event. R5-3D highlights a very good prediction of this phenomenon. After that, the measured MFR experiences a large fluctuation, considerably higher than the uncertainty band. Nevertheless, a good agreement is found between the average experimental data (around 3\% of the pre-transient value) and the simulation results. In this phase of the test, both temperatures of PIOTA rows 2 and 6 show a gradually decrease (Figure 6d). R5-3D well reproduces the first three minutes of the fifth PhW. Afterwards, the temperatures of the two PIOTAs converge to the same value, approaching an average temperature between the two experimental acquisitions. Several reasons could explain this discrepancy (e.g., assemblies-to-bypass heat transfer and measurement uncertainties), but the most reasonable one seems related to the assumptions of the calculations. First of all, as mentioned in section 4.2, constant k-loss coefficients are imposed at the inlet of each assembly, even if they should be a function of the flow rate. The k-loss coefficients have been calibrated based on specifications provided for the pre-transient operation (Sumner, 2018) and they could affect the flow distribution under different operation phases. In a similar manner, core power distribution has been calculated based on the pre-transient data and the same one is kept throughout the test. There is no evidence that the power distribution remains constant over the whole test and this, with the above-mentioned flow distribution, can explain discrepancies on the PIOTAs temperatures under natural circulation.

On the primary HTS, an overall good agreement is observed in the cold leg temperature (Figure 6b). A slight overprediction is still observed, due to the uncertainties related to the secondary loop boundary conditions (Figure 6a - see first PhW discussion). As regards the primary hot leg, a good prediction is observed up to $200 \mathrm{~s}$, when the temperature remains almost constant due to the large thermal inertia of the RV outlet plenum. After that, TCs observe a small temperature decrease throughout the test. On the contrary, R5-3D predicts a slight temperature increase up to $750 \mathrm{~s}$, when the maximum temperature is reached $(8 \mathrm{~K}$ higher than pre-transient value). Several phenomena affect the hot leg temperature (e.g., core outlet temperature, thermal stratification and mixing convection within RV outlet plenum, thermal inertia, and heat losses). There is not available thermalhydraulic data in the flow path connecting core outlet and hot leg, and thus it is difficult to identify the origin of such disagreement. Thermal-hydraulic phenomena within outlet plenum are analysed in section 5.3. A possible source of discrepancy is here presented. Stover et al. (1982) analysed the main outcomes of the pre-operational testing performed on FFTF in 1982. Among the parameters involved in the investigation, piping thermal stratification was analysed. Two transient scenarios were considered: reactor scram to pony motor flow and reactor scram to natural circulation flow. In those cases, reactor scram avoided the temperature increase across core assemblies, resulting in colder sodium exiting the core. The consequent outlet plenum stratification causes cold sodium to move directly from the core to the hot leg (see also discussion in section 5.3), producing a fast thermal down ramp. In case of transition to pony motor operation, sodium MFR is enough to avoid piping thermal stratification. On the contrary, when transition to natural circulation occurred, piping thermal stratification was 
experienced in the horizontal pipeline at the RV outlet. Cold sodium enters the hot leg, and the natural circulation flow was not enough to prevent such a phenomenon. Similarly, following a LOFWOS transient, the RV outlet plenum is gradually warm-up and hotter sodium enters the primary hot leg. This could cause piping thermal stratification just downstream the RV outlet and TC's measurement could be affected by their vertical position in the pipeline. On the other hand, R5-3D simulates the horizontal pipeline with a one-dimensional component in which, in case of single-phase flow (this is the case), homogenous thermodynamic conditions are employed along non-axial flow direction. Therefore, such model does not allow the simulation of thermal stratification phenomena within horizontal pipeline, explaining the discrepancy observed in Figure 6b.

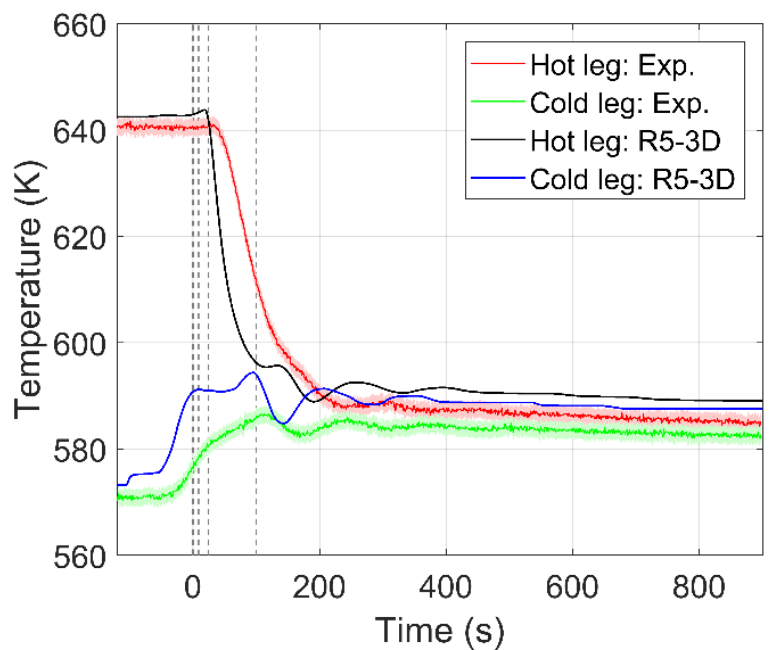

(a)

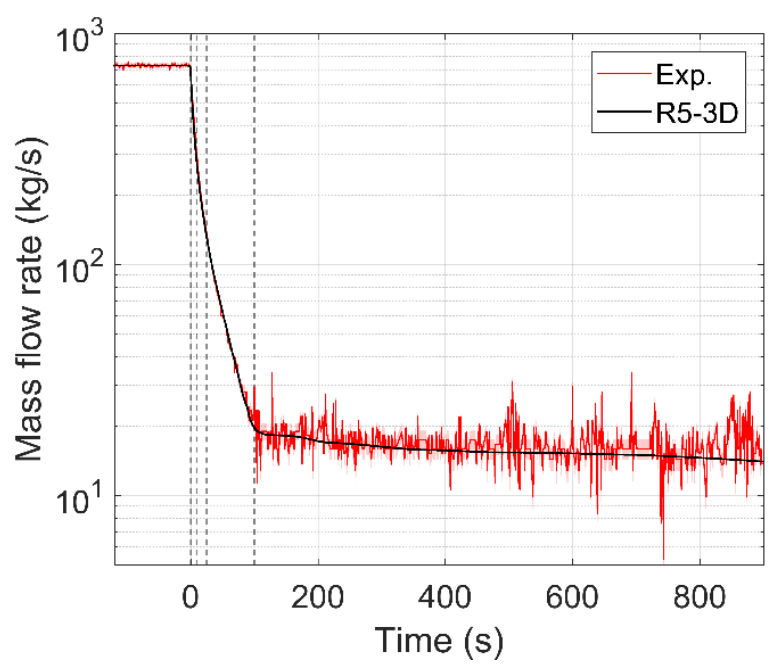

(c)

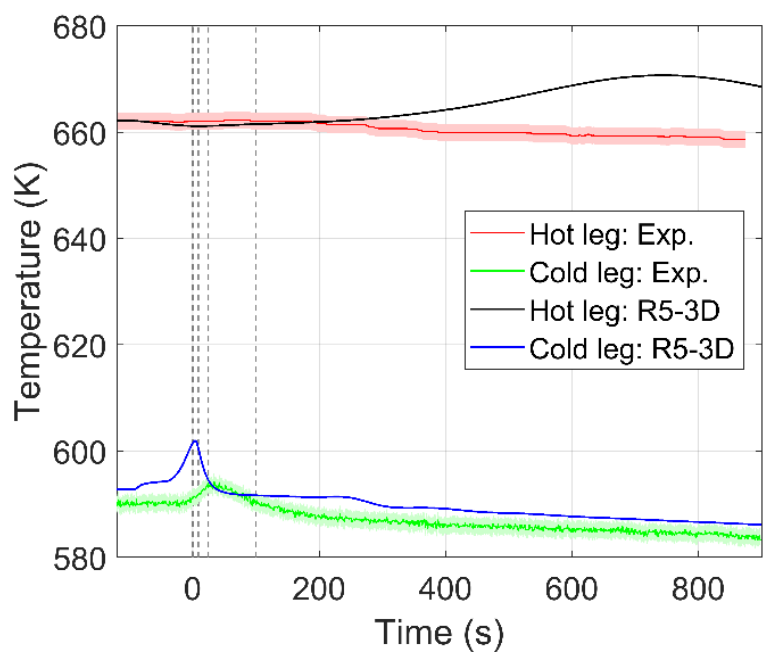

(b)

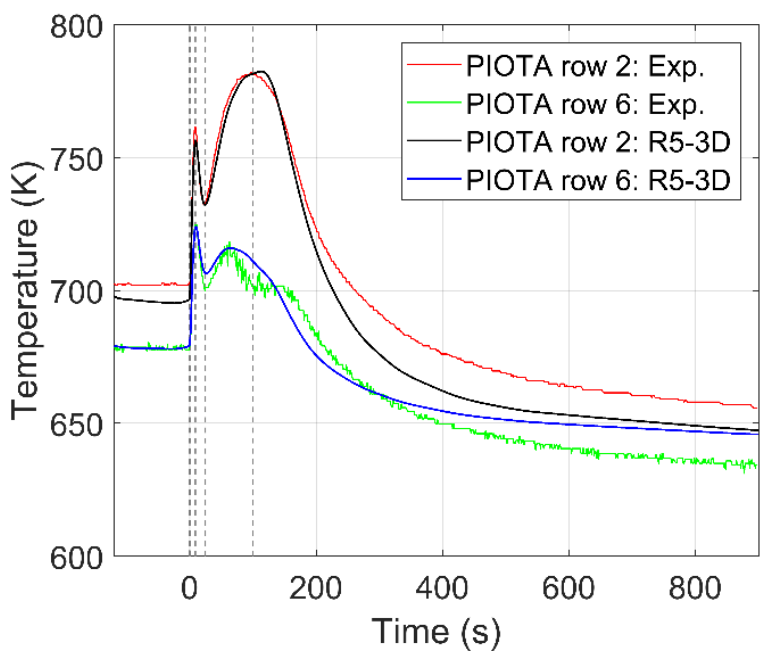

(d)

Figure 6. LOFWOS Test \#13 results: secondary loop 3 hot and cold leg temperatures (a), primary loop 3 hot and cold leg temperatures (b), primary sodium mass flow rate through loop 3 (c) and PIOTAs outlet temperature (d)

\subsection{Outlet plenum thermal stratification}

Thermal stratification is recognized as a crucial safety aspect for LMFRs because it could suppress the establishment of natural circulation as well as may enhance thermal fatigue cracking jeopardizing the integrity 
of the reactor vessel and its internal components. For example, it was identified as one of the main concerns in the earlier ALFRED configuration, encouraging the design review of the reactor (Alemberti et al., 2020; Narcisi et al., 2020b). This phenomenon can be induced by heat losses from hotter components to cold tanks (typical for pool-type reactors) or following a transient event involving the injection of fluid into a large volume with different temperature (in both pool-type and loop-type systems).

Several experimental activities were committed to increasing knowledge of such phenomenon. Scaled facilities were dedicated to investigating thermal stratification using water and sodium (leda et al., 1990; Tanaka et al., 1990) or LBE (Tarantino et al., 2015; Lorusso et al., 2019b). Furthermore, the Japanese MONJU and the French Phénix reactors provided useful data for the analysis of thermal stratification phenomena in SFRs (Doi and Muramatsu, 1997; Bandini et al., 2015a).

Wu et al. (2020) has presented a comprehensive review of the thermal stratification modelling procedures for SFRs. Three macro-areas have been distinguished: system-level calculations, Computational Fluid Dynamics (CFD) methods and STH/CFD coupling approaches. Examples of such applications are given by Narcisi et al. (2019b; 2019c) and Bandini et al. (2015b) for STH simulations, Zwijsen et al. (2019), Edemetti et al. (2019) and Buzzi et al. (2020) for CFD calculations and Bandini et al. (2015a) and Pucciarelli et al. (2020) for STH/CFD coupling methodologies.

In the frame of the FFTF pre-operational testing performed in 1982, one of the objectives was the investigation of the thermal transient patterns within the RV outlet plenum. Two tests were used to study thermal stratification and mixing convection during postulated transient scenarios: a loss of flow test, starting from $100 \%$ power and flow, moving to natural circulation after scram, and scram test with transition to pony motor flow. For this purpose, the RV outlet plenum was equipped with several TCs, installed at different levels within the large tank (Stover et al., 1982). The analysis revealed that, following a reactor scram to natural circulation, the plenum immediately developed stratified, due to the colder sodium coming from the core assemblies. The temperature increased continuously with the elevation without sharp changes, except just above the outlet nozzles, where an abrupt temperature increase was observed (around $56 \mathrm{~K}$ ). It was explained by the complete absence of turbulent mixing: cold sodium exited core assemblies and moved directly towards hot leg inlets. Somewhat different was observed in case of reactor scram to pony motor flow transient. In this case, turbulent mixing zone was partially established, and the thermal front was detected few meters above the outlet nozzles. Something like that was found in other computational activities, involving the Japanese MONJU (Shibahara et al., 2013) and the French Phénix (Narcisi et al., 2020a) reactors.

The experimental observations performed in the pre-operational testing are taken as reference in the present analysis. The R5-3D best practice guidelines in modelling such phenomena (Narcisi et al., 2019c) have been considered in the present work.

Figure 7 shows R5-3D prediction of the thermal pattern within the RV outlet plenum in six relevant moments of the LOFWOS Test \#13. The color bar has been selected to best specify temperature within the RV outlet plenum (refer to the online version of the paper for colored pictures). Thus, temperatures lower than $650 \mathrm{~K}$ are depicted in dark blue. During pre-transient operation, hot sodium exits core assemblies and mixes in the colder plenum. Hot sodium moves upward in the central part of the tank, cools and moves downward to the outlet nozzles (see Figure 7a). Unlike what was observed in the pre-operational testing, in LOFWOS Test \#13 scram command is not operated and, as shown in section 5.2, core outlet temperature increases in the first seconds of the test. It results in a warming up of the central region of the outlet plenum, which enhances the sodium mixing at the beginning of the test (Figure 7b). It leads to the heating of the upper region of the RV and the formation of a slight thermal front, as shown in Figure 7c. As the upper region warms, the thermal front moves downward (see Figure 7d), 
Nuclear Engineering and Design, 383 (2021) 111405, https://doi.org/10.1016/i.nucengdes.2021.111405

reaching the bottom of the outlet plenum around $300 \mathrm{~s}$ after the initiating event (Figure 7e). At this time, core temperature becomes colder than the outlet plenum and the sodium flow path involves only the bottom region of the plenum (Figure 7e). Now thermal-hydraulic conditions are similar to the one observed during the preoperational testing. Cold sodium exits the core assemblies moving directly towards the RV outlet nozzles. The upper region of the outlet plenum is not interested by the flow path, promoting the establishment of the thermal stratification just above the outlet nozzles. In these conditions a thermal front of about $20 \mathrm{~K}$ is predicted by the code.

The present analysis has been performed with an average mesh along a z-coordinate of $200 \mathrm{~mm}$. A mesh sensitivity study, involving different discretization on axial coordinate, has demonstrated the adequacy of this nodalization in the evaluation of thermal stratification and mixing convection phenomena. In addition, the effect of the axial thermal conduction within the primary coolant has been assessed, with a procedure described by Narcisi et al. (2019c). Such approach foresees the simulation of conductive heat transfer with specific heat structures applied between adjacent control volumes along the vertical coordinate. Figure 8 provides a schematic view of the methodology. A system of three control volumes, arranged in the vertical direction, is considered. Each volume has a specific temperature, namely $T_{1}, T_{2}$, and $T_{3}$. In case of stagnant (or quasi-stagnant) conditions, heat exchange between these control volumes is governed by thermal conduction. In such conditions, R5-3D does not account for any heat transfer, being negligible the one associated to the mass transfer (quasi-stagnant conditions). Such thermal-hydraulic problem can be modelled with the electric analogy presented in Figure 8. Each control volume is represented by a thermal node with a specific temperature. In case of stagnant conditions, the heat transfer is governed by the temperature difference between adjacent volumes and by the conductive thermal resistances $\left(R_{1-2}\right.$ and $\left.R_{2-3}\right)$. Such heat transfer scheme can be reproduced with R5-3D adding a heat structure in the interphase between adjacent control volumes. These control volumes represent the left and right boundaries of the heat structure. In the case presented in Figure 8, two heat structures are required to simulate $R_{1-2}$ and $R_{2-3}$. For a generic heat structure, the user can define the number of heat transfer mesh points (e.g., six per each heat structure in this case - see the scheme on the right in Figure 8). The heat structures are composed of a fake material that considers the thermal conductivity of the coolant contained in the fluid domain and a negligible heat capacity. Such methodology allows to reproduce the correct conductive heat transfer while not intervening in the thermal inertia. It is worth to emphasize that the mass of the coolant is already account in the fluid domain and, thus, it must be omitted in the heat structure. As presented in Figure 8 , the heat structures have a thickness equal to the distance of adjacent volumes' centers, and the heat transfer area equal to the flow area of the fluid domain. Moreover, to make negligible the thermal resistances related to convective heat transfer coefficients, high fouling factors are applied to both left and right boundaries of the heat structure. Note that such factors are thought to account for the fouling on the heat transfer surface (value less than one). Nevertheless, R5-3D also allows to specify a fouling factor higher than one, to improve the heat transfer limiting, or avoiding in this case, the convective thermal resistance. In this way, the temperatures of the external heat transfer mesh points coincide with the ones of control volumes used as boundaries, as presented in Figure 8 . The simulation performed with this thermal conduction model has demonstrated its negligible effect on the thermal front establishment. Such outcome is not surprising. Indeed, Yoo et al. (2003) proposed a methodology to assess the relative importance of axial coolant conduction with respect to convection, based on the Peclet number $(P e=R e \cdot P r)$. This non-dimensional parameter expresses the relative importance of convection and radial conduction contributes to heat transfer in a pipe. When $P e>>1$ heat conduction can be considered negligible. Referring to axial conduction, Yoo et al. (2003) proposed a modified Peclet number defined as $P e^{*}=\operatorname{Re} \cdot \operatorname{Pr} \cdot\left(L / D_{h}\right)$, where $L$ is the axial length. They found that thermal conduction through the axial coordinate is negligible when $P e^{*}>>100$. Therefore, it is usually appropriate to neglect fluid axial heat conduction in liquid metal-cooled fast reactors under normal operation, but in particular conditions, such as start-up phase or accidental scenario, the 
importance of this heat transfer mode must be assessed. In the present case, after the transition event, $P e^{*}$ assumes a value between 100 and 1000, confirming the outcomes obtained with R5-3D. Regarding the radial conduction, it has been neglected in the present study because the $P e$ is always higher than one and, furthermore, a significant gradient of temperature along radial coordinate is visible only during normal operation (when nominal flow conditions are kept) and in the first minutes of the transient.

It is worth to underline that the presence of internal structures within the RV outlet plenum (e.g., control rod drivelines, in-vessel handling machine, instrument tree and low-level flux monitoring system) is not considered in the modelling, since they were not listed in the benchmark specifications. It is plausible that internal components could play an important role in the fluid dynamics within the large plenum and, thus, affect reliability of the computational results.

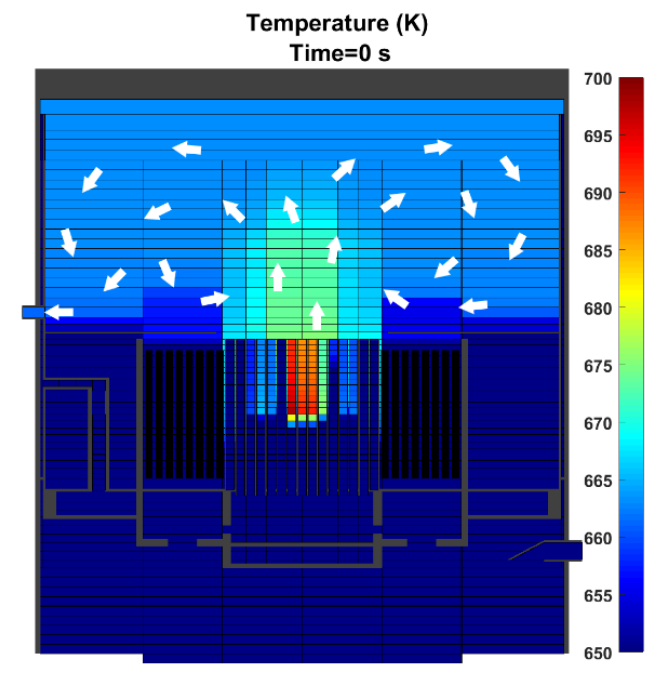

(a)



(c)

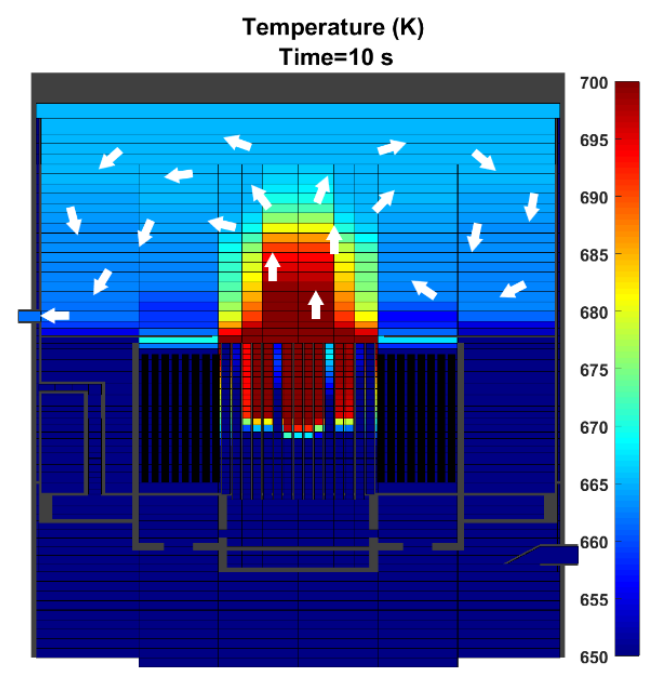

(b)

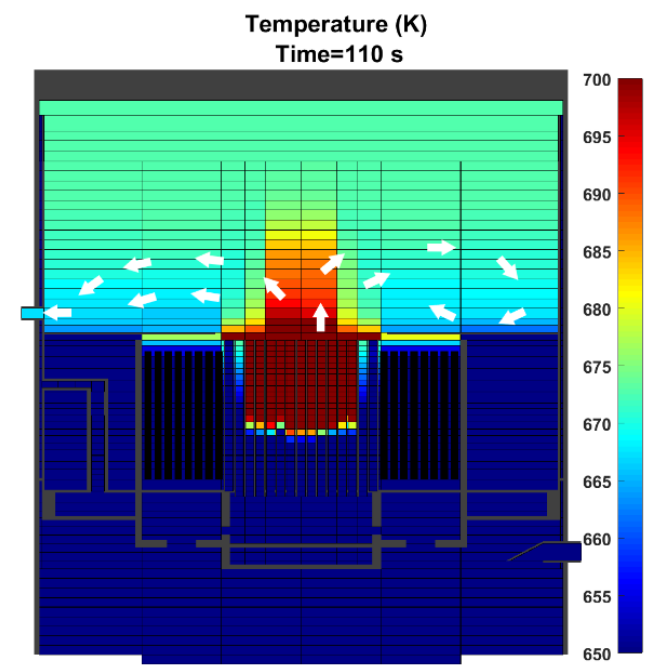

(d) 


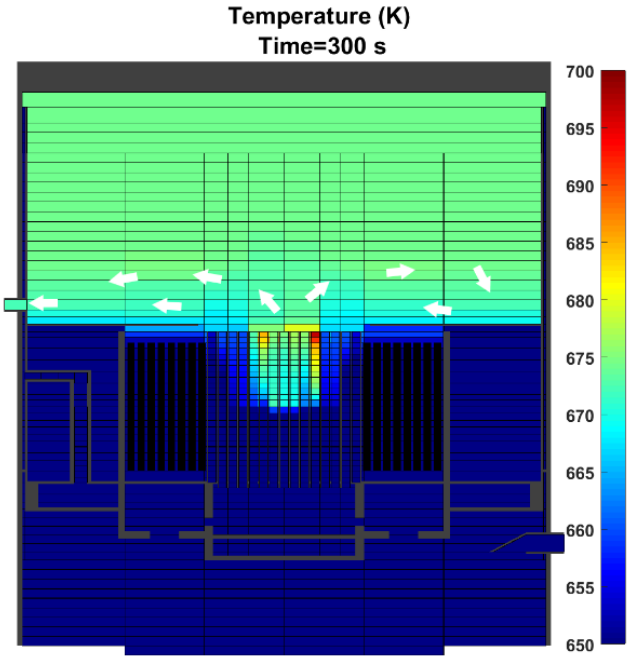

(e)

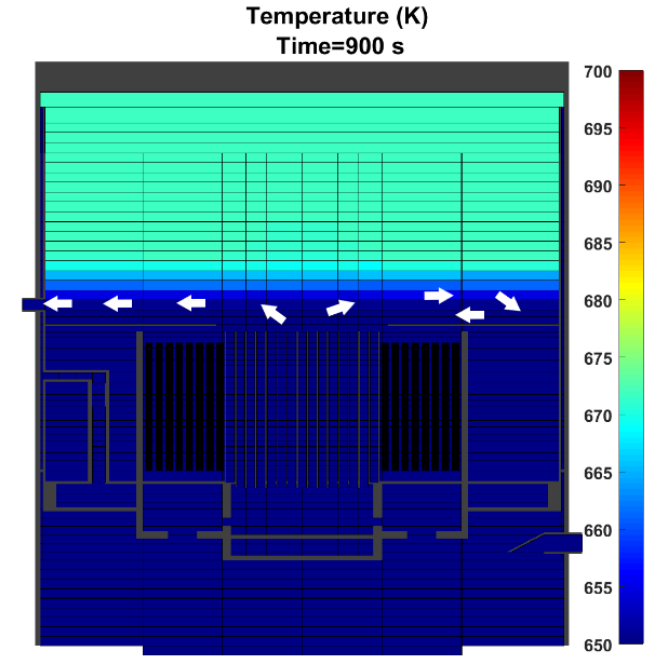

(f)

Figure 7. RV thermal pattern throughout LOFWOS Test \#13

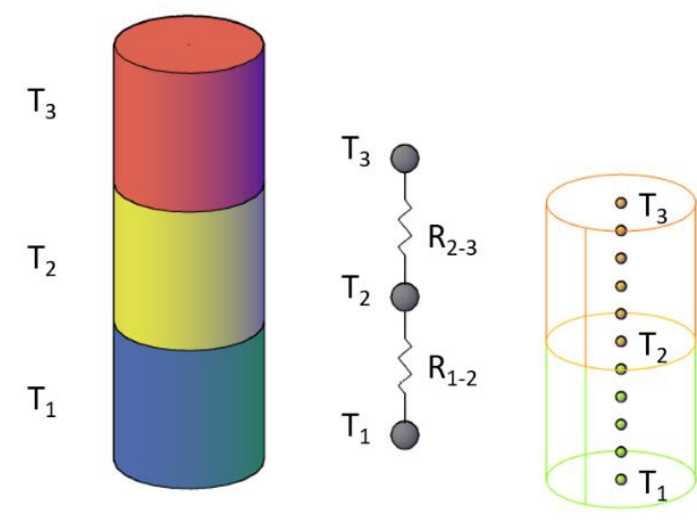

Figure 8. Modelling of conductive heat transfer

\subsection{Free surface motion}

One of the most relevant peculiarities of FFTF was the adoption of the GEM passive safety device, which provides significant negative reactivity feedback following a loss of flow transient. The rate and the magnitude of such reactivity depend on the speed of the coastdown and the final level reached within the GEM.

This aspect is fundamental for the neutronic model of the GEM because the PHISICS model prepared for the coupling (not included in this paper) is capable to simulate both the sodium density and the sodium temperature effect (as the water into the Boiling Water Reactors), considering the effective position of the sodium into the module for evaluating the reactivity during the transient.

For this, the success of a NK/TH coupled calculation strictly relies on a good evaluation of the free surface motion by R5-3D. For this reason, the capabilities of the code to reproduce the movement of the liquid metal have been investigated and the main outcomes, preparatory for the next NK/TH phase, are discussed in the present section.

This specific computational topic for liquid metal applications is barely treated in literature. Narcisi et al. (2018) used R5-3D in the pre-test phase of an experimental campaign performed in CIRCE facility (Lorusso et al., 2019b) 
to evaluate the LBE free surface motion within the hot plenum and verify the adequacy of the design. The free level motion during the postulated loss of flow test was also investigated.

FFTF foresaw three liquid metal surfaces: at the RV top, in the equalizing lines and within the GEMs. The nodalization adopted for the analysis has been extensively described in section 4.2. To recap the modelling choices, each free level is simulated with a single vertical pipe component that allows the free surface motion during the transient. The axial meshing is conceived to preserve the sliced approach. The mixture level tracking model has been activated in each of these components, ensuring a stabler calculation.

Figure 9 summarizes the main outcomes of the analysis. For each chart, BAF has been assumed as zero level. The free levels computed by R5-3D at the RV top and within the equalizing lines are compared in Figure 9a. The original level difference corresponds to the pressure losses between the reactor vessel and the primary pumps (around $5 \mathrm{kPa}$ ). The RV sodium level remains almost constant throughout the test, showing only a slight increase after the initiator event, due to the average temperature increase in the first phase of the test. Following the transition event, the free surface within the equalizing line experienced an abrupt increase and, unless the initial fluctuations, approximatively matches the RV level. This is due to the drop of the pressure losses, following the sodium flow rate coastdown. The residual discrepancy between the two levels establishes for the pressure losses in natural circulation.

The GEM free surface motion is analyzed in Figure 9b, where the case identified as "Reference" represents the calculation carried out assuming the initial reference level of $1.213 \mathrm{~m}$ (Sumner, 2018). In order to provide a comprehensive assessment of the GEM thermal-hydraulics, some boundary conditions are changed and their effects on the final level are analyzed. The parameters subjected to the sensitivity analysis have been the initial GEM level, the RV level, the RV cover gas pressure, and the GEM-to-bypass heat transfer. Among these, only the initial GEM level has shown relevancy in the free surface motion. Figure $9 \mathrm{~b}$ compares the reference calculation with the simulations performed assuming $+/-10 \%$ of the initial level. Given that the gas pressure within the GEM is almost the same at the beginning of the simulations (it depends on the inlet core pressure), initial level change results in a different number of gas moles contained in the GEM's expansion volume. It determines not only the magnitude of the level change, but also the required time for the total reactivity insertion (i.e., the needed time for the sodium level to move below the BAF). Figure $9 \mathrm{~b}$ shows that the reference calculation and the one identified as "-10\%" presents enough gas to expand over the BAF whereas, in case of augmented free level $(+10 \%)$, the final sodium surface established $248 \mathrm{~mm}$ above the BAF. It has been recognized that an increase of $5 \%$ of the initial reference level leads the cover gas to expand up to the BAF. Concerning the required time for the total reactivity insertion, the reference simulation needs $26 \mathrm{~s}$ for the complete insertion whereas, assuming a lower initial sodium level (-10\%), $15 \mathrm{~s}$ are needed.

The present analysis provides useful outcomes for the NK/TH computational campaign, which will clarify the whole effects of such changes. 


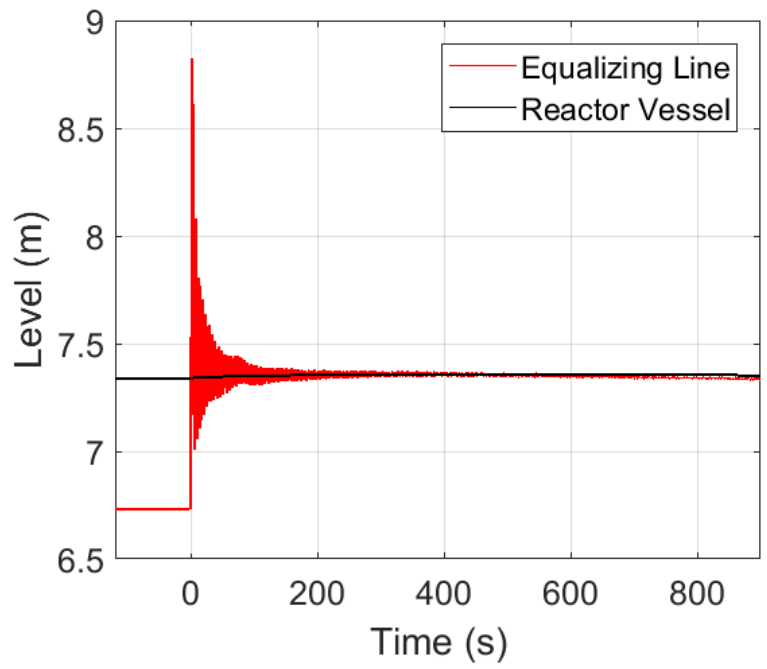

(a)

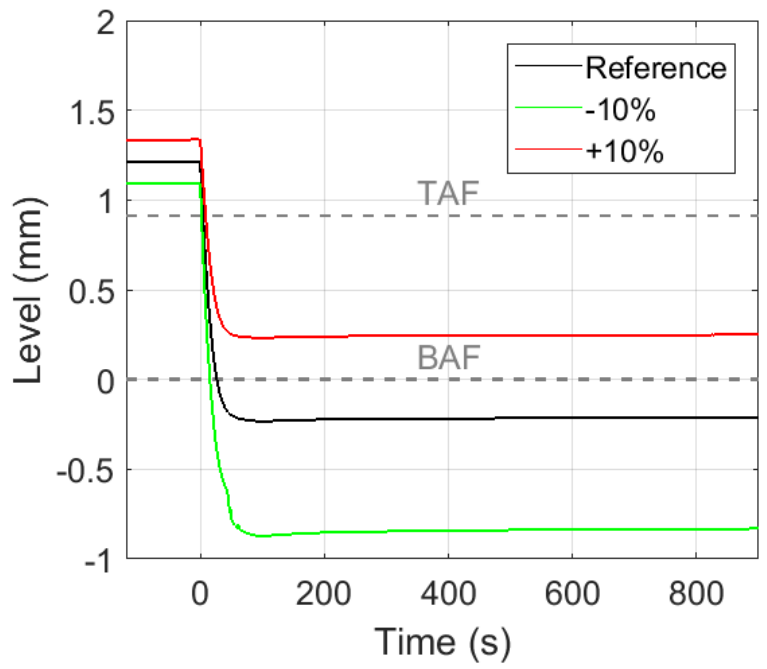

(b)

Figure 9. Free surface motion: equalizing line, RV (a) and GEM (b)

\section{Conclusions}

In 2018, the DIAEE of Sapienza University of Rome expressed their interest to participate to the CRP promoted by the IAEA for the FFTF LOFWOS test, aiming at the assessment of existing numerical tools for simulation of transient events in LMFRs. FFTF was a loop-type SFR, operated in USA from 1980 to 1992. It was designed as an SFR demonstrator with the aim to prove safety, reliability, and economic competitiveness of SFR nuclear power plants. One of the most relevant peculiarities of this reactor was the fully integrated passive devices that had to guarantee the safety cooling down of the system following accidental scenarios.

In this framework, the DIAEE has developed a detailed multiphysics modelling based on a NK/TH coupling approach involving RELAP5-3D ${ }^{\odot}$ and PHISICS codes. The present paper deals with the validation of the standalone thermal-hydraulic model, as a preliminary phase of the multiphysics calculation. The LMFR modelling best practice guidelines discussed in the literature have been adopted. The nodalization consists of two macroregions: a 3D scheme of the reactor vessel and a 1D model of the reactor core and the HTSs. The comparison between the steady-state results and the benchmark specifications has demonstrated the capability of the code to reproduce pre-transition operation and has proven the correctness of the TH modelling.

Steady-state results have been used as initial conditions for the transient analysis. Simulation outcomes have been compared with experimental data, provided at the end of the blind phase of the benchmark. The transient analysis has highlighted an overall good agreement with the experiment. The code has shown its capability to reproduce each relevant phenomenon observed in the test: e.g., the sudden core temperature rise following the power-to-flow ratio increase, the flow rate coastdown and the establishment of the natural circulation and the long-term reactor cooling. Some minor criticalities have been observed, mainly related to uncertainties on the secondary HTS operation. However, disagreements on the HTS temperatures do not affect reactor core behaviour and natural circulation establishment, since the large thermal inertia of the RV inlet plenum absorbs the slights differences obtained in the primary and secondary loops. Nevertheless, further investigations are needed to explain the observed disagreements, and interaction with benchmark community could help the understanding of the origin of such discrepancies. 
Furthermore, two relevant phenomena characterizing the LMFRs operation have been investigated. Regarding the outlet plenum thermal stratification, the evolution of the flow pattern within the large volume has been comprehensively analysed and experimental data derived from the FFTF pre-operational testing have been used to qualitatively assess the simulation results. Concerning the free surface motion, simulation results have shown a plausible transition of the free level within the RV and the equalizing line. In addition, a sensitivity analysis has revealed the initial GEM level as the most relevant parameter that could affect the rate and the magnitude of the reactivity feedback insertion.

Future works will be dedicated to the improvement of the knowledge of the LOFWOS Test \#13, aiming at reducing the minor discrepancies observed in the present work, and to run the NK/TH coupled calculations, which will clarify the influence of thermal-hydraulic parameters on the neutron economy.

\section{Acknowledgements}

The data and information presented in the paper are part of an ongoing IAEA coordinated research project on "Benchmark Analysis of Fast Flux Test Facility (FFTF) Loss of Flow Without Scram Test - CRP-I32011". The authors wish to thank IAEA, in particular Vladimir Kriventsev and Chirayu Batra, for the promoting, managing, and supporting the CRP, alongside with Argonne National Laboratory, in particular Sumner Tyler, for providing experimental data.

\section{Acronyms}

$\begin{array}{ll}\text { 1D } & \text { One-dimensional } \\ \text { 3D } & \text { Three-dimensional } \\ \text { ALFRED } & \text { Advanced Lead Fast Reactor European Demonstrator } \\ \text { BAF } & \text { Bottom of Active Fuel } \\ \text { CFD } & \text { Computational Fluid Dynamics } \\ \text { CR } & \text { Control Rod } \\ \text { CRP } & \text { Coordinated Research Project } \\ \text { DFA } & \text { Driver Fuel Assembly } \\ \text { Dh } & \text { Hydraulic Diameter } \\ \text { DHX } & \text { Dump Heat Exchanger } \\ \text { DIAEE } & \text { Department of Astronautical, Electrical and Energy Engineering } \\ \text { f } & \text { Friction factor } \\ \text { FFTF } & \text { Fast Flux Test Facility } \\ \text { FMA } & \text { Fracture Mechanics Assembly } \\ \text { FZ } & \text { Flow Zone } \\ \text { GEM } & \text { Gas Expansion Module } \\ \text { HTC } & \text { Heat Transfer Coefficient } \\ \text { HTS } & \text { Heat Transport System } \\ \text { IAEA } & \text { International Atomic Energy Agency } \\ \text { ICSA } & \text { In Core Shim Assembly } \\ \text { IHX } & \text { Intermediate Heat Exchanger } \\ \text { L } & \text { Laminar }\end{array}$




$\begin{array}{ll}\text { LBE } & \text { Lead-Bismuth Eutectic alloy } \\ \text { LMFR } & \text { Liquid Metal-cooled Fast Reactors } \\ \text { LOFWOS } & \text { Loss Of Flow Without Scram } \\ \text { MFR } & \text { Mass Flow Rate } \\ \text { MOTA } & \text { Material Open Test Assembly } \\ \text { MULTID } & \text { Multi-dimensional } \\ \text { NK/TH } & \text { Neutron-Kinetic/Thermal-Hydraulic } \\ \text { Pe } & \text { Peclet number } \\ \text { PhW } & \text { Phenomenological Window } \\ \text { PIOTA } & \text { Proximity Instrumented Open Test Assemblies } \\ \text { Pr } & \text { Prandtl number } \\ \text { R } & \text { Surface Roughness } \\ \text { R5-3D } & \text { RELAP5-3D }{ }^{\circ} \\ \text { Re } & \text { Reynolds number } \\ \text { RV } & \text { Reactor Vessel } \\ \text { SESAME } & \text { thermal-hydraulics Simulation and Experiment for the Safety Assessment of Metal cooled } \\ & \text { reactor } \\ \text { SFR } & \text { Sodium-cooled Fast Reactor } \\ \text { SR } & \text { Safety Rod } \\ \text { STH } & \text { System Thermal-Hydraulic } \\ \text { T } & \text { Turbulent } \\ \text { TAF } & \text { Top of Active Fuel } \\ \text { TC } & \text { Thermocouple } \\ \text { TH } & \text { Thermal-Hydraulic } \\ & \end{array}$

\section{References}

Alemberti, A., Caramello, M., Frignani, M., Grasso, G., Merli, F., Morresi, G., Tarantino, M., 2020. ALFRED reactor coolant system design. Nucl. Eng. Des. 370, 110884. https://doi.org/10.1016/j.nucengdes.2020.110884

Alfonsi, A., Epiney, A.S., Wang, Y., Balestra, P., Rabiti, C., 2019. PHISICS User Manual. INL-EXT-19-55002, Idaho Falls, Idaho, USA.

Bandini, G., Polidori, M., Gerschenfeld, A., Pialla, D., Li, S., Ma, W.M., Kudinov, P., Jeltsov, M., Kööp, K., Huber, K., Cheng, X., Bruzzese, C., Class, A.G., Prill, D.P., Papukchiev, A., Geffray, C., Macian-Juan, R., Maas, L., $2015 a$. Assessment of systems codes and their coupling with CFD codes in thermal-hydraulic applications to innovative reactors. Nucl. Eng. Des. 281, 22-38. https://doi.org/10.1016/j.nucengdes.2014.11.003

Bandini, G., Polidori, M., Meloni, P., Tarantino, M., Di Piazza, I., 2015b. RELAP5 and SIMMER-III code assessment on CIRCE decay heat removal experiments. Nucl. Eng. Des. 281, 39-50 http://dx.doi.org/10.10167j.nucengdes.2014.11.005

Briggs, L., 2013. Benchmark Analyses of the Shutdown Heat Removal Tests Performed in the EBR-II Reactor. In Proc. IAEA International Conference of Fast Reactors and Related Fuel Cycles: Safe Technologies and Sustainable Scenarios, March 4-7, Paris, France.

Buzzi, F., Pucciarelli, A., Galleni, F., Tarantino, M., Forgione, N., 2020. Analysis of thermal stratification phenomena in the CIRCE-HERO facility. Ann. Nucl. Energy 141, 107320.

https://doi.org/10.1016/i.anucene.2020.107320 
Nuclear Engineering and Design, 383 (2021) 111405, https://doi.org/10.1016/i.nucengdes.2021.111405

Castelliti, D. and Hamidouche, T., 2017. Comparison of MYRRHA RELAP5 MOD 3.3 and RELAP5-3D Models on Steady State and PLOF Transient. Nucl. Technol. 193 (1), 36-46. https://doi.org/10.13182/NT14-139

Cheng, S.K., Todreas, N.E., 1986. Hydrodynamic models and correlations for bare and wire-wrapped hexagonal rod bundles - Bundle friction factors, subchannel friction factors and mixing parameters. Nucl. Eng. Des., 92, 227-251. https://doi.org/10.1016/0029-5493(86)90249-9

Ciurluini, C., Narcisi, V., Giannetti, F., Cretara, L., Caruso, G., 2020. Preliminary neutron kinetic - thermal hydraulic coupled analysis of the ALFRED reactor using PHISICS/RELAP5-3D. J. Phys. Conf. Ser. 1599, 012023. doi:10.1088/1742-6596/1599/1/012023

Colebrook, C.F., 1939. Turbulent Flow in Pipes with Particular Reference to the Transition Region Between Smooth and Rough Pipe Law. J. I. Civil Eng. 11, 133-156.

Davis, C.B., 2006. Applicability of RELAP5-3D for Thermal-Hydraulic Analyses of a Sodium-Cooled Actinide Burner Test Reactor. INL/EXT-06-11518, Idaho Falls, Idaho, USA.

Del Nevo, A. and Martelli, E., 2016. Validation of a Three-Dimensional Model of EBR-II and Assessment of RELAP5-3D Based on SHRT-17 Test. Nucl. Technol. 193, 1-14. http://dx.doi.org/10.13182/NT14-152

Doi, Y., Muramatsu, T., 1997. Numerical analysis of thermal of thermal stratification phenomena in upper plenum of fast breeder reactor. Proc. 8th International Topical Meeting on Nuclear Reactor ThermalHydraulics, 3, 1696-1703.

Edemetti, F., Tassone, A., Narcisi, V., Giannetti, F., Ferroni, L., Tarantino, M., 2019. Numerical analysis of temperature stratification in the CIRCE pool facility. J. Phys. Conf. Ser. 1224, (012007). https://doi.org/10.1088/1742-6596/1224/1/012007

Forgione N., Martelli D., Barone G., Giannetti F., Lorusso P., Hollands T., Papukchiev A., Polidori M., Cervone A., Di Piazza I., 2019. Post-test simulations for the NACIE-UP benchmark by STH codes. Nucl. Eng. Des. 353, 110279. https://doi.org/10.1016/j.nucengdes.2019.110279

Giannetti, F., 2018. Sapienza University of Rome Contribution to IAEA CRP Benchmark analysis of FFTF loss of flow without scram test. Presentation delivered at the 1st RCM of the IAEA CRP I31032, October 2018, Vienna, Austria.

IAEA, International Atomic Energy Agency. Benchmark Analysis of FFTF Loss of Flow Without Scram Test. https://www.iaea.org/projects/crp/i32011

leda, Y., Maekawa, I., Muramatsu, T., Nakanishi, S., 1990. Experimental and analytical studies of the thermal stratification phenomenon in the outlet plenum of fast breeder reactors. Nucl. Eng. Des. 120 (2-3), 403-414. https://doi.org/10.1016/0029-5493(90)90390-J

Kazimi, M.S. and Carelli, M.D., 1976. Clinch River Breeder Reactor Plant Heat Transfer Correlation for Analysis of CRBRP Assemblies. CRBRP-ARD-0034, Westinghouse.

Liu, Y., Hu, R., 2020. Benchmark Modeling and Simulation of the FFTF LOFWOS Test \#13 Using SAM. ANL/NSE20/8, Argonne, USA. Available online: https://www.osti.gov/biblio/1671789

Lorusso, P., Pesetti, A., Tarantino, M., Narcisi, V., 2019a. Protected loss of flow accident simulation in CIRCEHERO facility: experimental test and system code assessment. Proc. 27th Int. Conf. Nucl. Eng. (ICONE-27), May 19-24 2019, Ibaraki, Japan. 
Nuclear Engineering and Design, 383 (2021) 111405, https://doi.org/10.1016/i.nucengdes.2021.111405

Lorusso, P., Pesetti, A., Tarantino, M., Narcisi, V., Giannetti, F., Forgione, N., Del Nevo, A., 2019b. Experimental analysis of stationary and transient scenarios of alfred steam generator bayonet tube in circe-hero facility. Nucl. Eng. Des. 352, 110169. https://doi.org/10.1016/j.nucengdes.2019.110169

Lorusso, P., Del Nevo, A., Narcisi, V., Giannetti, F., Caruso, G., Zwijsen, K., Breijder, P.A., Hamidouche, T., Castelliti, D., Rozzia, D., Tarantino M., 2021. Total loss of flow benchmark in CIRCE-HERO integral test facility. Nucl. Eng. Des. 376, 111086. https://doi.org/10.1016/j.nucengdes.2021.111086

Mascari, F., Vella, G., Woods, B.G., Welter, K., Pottorf, J., Young, E., Adorni, M., D’Auria, F., 2011. Sensitivity analysis of the MASLWR helical coil steam generator using TRACE. Nucl. Eng. Des. 241 (4), 1137-1144. https://doi.org/10.1016/j.nucengdes.2010.05.002

Memmott, M., Buongiorno, J., Hejzlar, P., 2010. On the use of RELAP5-3D as a subchannel analysis code. Nucl. Eng. Des. 240, 807-815. https://doi.org/10.1016/j.nucengdes.2009.11.006

Narcisi, V., Giannetti, F., Del Nevo, A., Tarantino, M., Caruso, G., 2018. Pre-test analysis of accidental transients for ALFRED SGBT mock-up characterization. Nucl. Eng. Des. 333, 181-195.

https://doi.org/10.1016/j.nucengdes.2018.04.015

Narcisi, V., Giannetti, F., Del Nevo, A., Alcaro, F., Wang, X., Kraus, A., Brunnett, A., Thomas, J., Girault, N., Grosjean, B., Caruso, G., Gerschenfeld, A., 2019a. System thermal-hydraulic modelling of the phénix dissymmetric test benchmark. Nucl. Eng. Des. 353, 110272. https://doi.org/10.1016/j.nucengdes.2019.110272

Narcisi, V., Giannetti, F., Del Nevo, A., Tarantino, M., Caruso, G., 2019b. Post-test simulation of a PLOFA transient test in the CIRCE-HERO facility. Nucl. Eng. Des. 355, 110321.

https://doi.org/10.1016/i.nucengdes.2019.110321

Narcisi, V., Giannetti, F., Caruso, G., 2019c. Investigation on RELAP5-3D@ capability to predict thermal stratification in liquid metal pool-type system and comparison with experimental data. Nucl. Eng. Des. 352, 110152. https://doi.org/10.1016/j.nucengdes.2019.110152

Narcisi, V., Giannetti, G., Subioli, A., Del Nevo, A., Caruso, G., 2020a. Assessment of a RELAP5-3D threedimensional analysis based on PHÉNIX dissymmetric transient test. J. Nuc. Eng. Rad. Sci. 6, 011301. https://doi.org/10.1115/1.4044847

Narcisi, V., Giannetti, F., Caramello, M., Caruso, G., 2020b. Preliminary evaluation of ALFRED revised concept under station blackout. Nucl. Eng. Des. 364, 110648. https://doi.org/10.1016/i.nucengdes.2020.110648

Nguyen, D.H., 1990. Role of feedback reactivities in the passive safety of nuclear reactors: the case of the Fast Flux Test Facility, Nucl. Technol. 91, 61-74. https://doi.org/10.13182/NT90-A34441

Pucciarelli, A., Galleni, F., Moscardini, M., Martelli, D., Forgione, N., 2020. STH/CFD Coupled Simulation of the Protected Loss of Flow Accident in the CIRCE-HERO Facility. Appl. Sci. 10, 7032. doi:10.3390/app10207032

Roelofs, F., 2019. Thermal Hydraulics Aspects of Liquid Metal Cooled Nuclear Reactors. Woodhead Publishing, Cambridge.

Seban, R.A. and Shimazaki, T.T., 1951. Heat Transfer to a Fluid Flowing Turbulently in a Smooth Pipe with Walls at Constant Temperature. T. ASME, 73, 803-809.

Sha, W. T. and Launder B. E., 1979. A model for turbulent momentum and heat transport in large rod bundles. ANL-77-73, Argonne National Laboratory, IL, USA. 
Shibahara, M., Takata, T., Yamaguchi, A., 2013. Numerical study on thermal stratification phenomena in upper plenum of LMFBR “MONJU”. Nucl. Eng. Des. 258, 226-234. http://dx.doi.org/10.1016/j.nucengdes.2013.02.007

Stover, R.L., Beaver, T.R., Chang, S.C., 1982. FFTF thermal-hydraulic testing results affecting piping and vessel component design in LMFBR's. Proc. ASME Pressure Vessel \& Piping Conference, June, Portland, Oregon, USA.

Sumner, T., 2018. Benchmark Analysis of Fast Flux Test Facility (FFTF) Loss of Flow Without Scram Test. IAEA CRP-I332011, ANL, USA.

Sumner, T., Moisseytsev, A., Stauff, N., 2020. LOFWOS Test \#13 measured test data. Presentation delivered at the informal online meeting of the IAEA CRP I31032 on Benchmark Analysis of Fast Flux Test Facility (FFTF) Loss of Flow Without Scram Test, October 2020, Vienna, Austria.

Tanaka, N., Moriya, S., Ushijima, S., Koga, T., Eguchi, Y., 1990. Prediction method for thermal stratification in a reactor vessel. Nucl. Eng. Des. 120 (2-3), 395-402. https://doi.org/10.1016/0029-5493(90)90389-F

Tarantino, M., Martelli, D., Barone, G., Di Piazza, I., Forgione, N., 2015. Mixed convection and stratification phenomena in a heavy liquid metal pool. Nucl. Eng. Des. 286, 61-277.

https://doi.org/10.1016/j.nucengdes.2015.02.012

The RELAP5-3D ${ }^{\odot}$ Code Development Team, 2015a. RELAP5-3D Code Manual Vol. I: Code Structure, System Models, and Solution Methods. INL/MIS-15-36723 Volume I, Revision 4.3, Idaho Falls, Idaho, USA.

The RELAP5-3D ${ }^{\odot}$ Code Development Team, 2015b. RELAP5-3D Code Manual Vol. IV: Models and Correlations. INL/MIS-15-36723 Volume IV, Revision 4.3, Idaho Falls, Idaho, USA.

Wootan, D.W., Omberg, R.P., Sofu, T., Grandy, C., 2017a. Passive Safety Testing at the Fast Flux Test Facility Relevant to New LMR Designs. In Proc. International Conference on Fast Reactor and Related Fuel Cycles, June 26-29, Yekaterinburg, Russia.

Wootan, D.W., Omberg, R.P., Grandy, C., 2017b. The U.S. Knowledge Preservation Program for Fast Flux Test Facility Data. In Proc. International Conference on Fast Reactor and Related Fuel Cycles, June 26-29, Yekaterinburg, Russia.

Wu, Z., Lu, C., Morgan, S., Bilbao y Leon, S., Bucknor, M., 2020. A status review on the thermal stratification modeling methods for Sodium-cooled Fast Reactors. Prog. Nucl. Energ. 125, 103369.

https://doi.org/10.1016/j.pnucene.2020.103369

Yoo Y.J., Sabharwall P., Reyes J.N., Wu Q., Sienicki J.J., 2003. Effects of the fluid axial conduction on liquid metal natural circulation and linear stability. In: 2003 ANS/ENS International Winter Meeting, New Orleans, LA, pp. 1523-1530.

Zigrang, D.J., Sylvester, N.D., 1985. A Review of Explicit Friction Factor Equations. J. Energ. Resour.-ASME 107, 280-283.

Zwijsen, K., Dovizio, D., Moreau, V., Roelofs, F., 2019. CFD modelling of the CIRCE facility. Nucl. Eng. Des. 353, 110277. https://doi.org/10.1016/i.nucengdes.2019.110277 